\title{
Mitochondrial transcript maturation and its disorders
}

\author{
Lindsey Van Haute ${ }^{1} \cdot$ Sarah F. Pearce $^{1} \cdot$ Christopher A. Powell $^{1}$ • \\ Aaron R. D'Souza ${ }^{1} \cdot$ Thomas J. Nicholls $^{1,2} \cdot$ Michal Minczuk $^{1}$
}

Received: 17 February 2015 /Revised: 27 April 2015 / Accepted: 29 April 2015 /Published online: 28 May 2015

(C) The Author(s) 2015. This article is published with open access at Springerlink.com

\begin{abstract}
Mitochondrial respiratory chain deficiencies exhibit a wide spectrum of clinical presentations owing to defective mitochondrial energy production through oxidative phosphorylation. These defects can be caused by either mutations in the mitochondrial DNA (mtDNA) or mutations in nuclear genes coding for mitochondrially-targeted proteins. The underlying pathomechanisms can affect numerous pathways involved in mitochondrial biology including expression of mtDNAencoded genes. Expression of the mitochondrial genes is extensively regulated at the post-transcriptional stage and entails nucleolytic cleavage of precursor RNAs, RNA nucleotide modifications, RNA polyadenylation, RNA quality and stability control. These processes ensure proper mitochondrial RNA (mtRNA) function, and are regulated by dedicated, nuclear-encoded enzymes. Recent growing evidence suggests that mutations in these nuclear genes, leading to incorrect maturation of RNAs, are a cause of human mitochondrial disease. Additionally, mutations in mtDNA-encoded genes may also affect RNA maturation and are frequently associated with human disease. We review the current knowledge on a subset of nuclear-encoded genes coding for proteins involved in mitochondrial RNA maturation, for which genetic variants impacting upon mitochondrial pathophysiology have been
\end{abstract}

Presented at the Annual Symposium of the Society for the Study of Inborn Errors of Metabolism, Innsbruck, Austria, September 2-5, 2014

Communicated by: Shamima Rahman

Michal Minczuk

michal.minczuk@mrc-mbu.cam.ac.uk

1 MRC Mitochondrial Biology Unit, Hills Road, Cambridge CB2 OXY, UK

2 Department of Medical Biochemistry and Cell Biology, University of Gothenburg, Gothenburg, Sweden reported. Also, primary pathological mtDNA mutations with recognised effects upon RNA processing are described.

\section{Introduction}

Mitochondria are cellular compartments present in every cell of the human body (except red blood cells) and are responsible for generating almost all of the energy needed to sustain life and to grow. In mitochondria, energy is produced in the process of oxidative phosphorylation (OXPHOS). The biogenesis of the OXPHOS system entails assembly of approximately 90 proteins into five complexes. Most of these proteins are encoded by DNA that is contained within the cell nucleus (nDNA). However, 13 of these are encoded within a small, circular genome inside mitochondria (Fig. 1). Recent research has identified defects in mitochondrial DNA (mtDNA) expression that are associated with a diverse group of human disorders characterised by impaired mitochondrial respiration (Nicholls et al 2013; Boczonadi and Horvath 2014). Many regulatory factors and pathways are involved in mitochondrial gene expression and establishing the molecular details of how defects in these processes contribute to human disease constitutes a major challenge.

In addition to messenger RNAs (mt-mRNAs), the human mitochondrial transcriptome also consists of two ribosomal RNAs (mt-rRNAs, $12 \mathrm{~S}$ and $16 \mathrm{~S}$ ) that are a part of the mitochondrial ribosome and a complete set of 22 transfer RNAs (mt-tRNAs) (Rorbach and Minczuk 2012) (Fig. 1). All of the mitochondrial protein factors necessary for RNA synthesis, endonucleolytic processing, post-transcriptional modifications, aminoacylation, RNA stability regulation, and RNA turnover along with the factors necessary for biogenesis of the mitochondrial ribosome and translation are encoded by nDNA and imported to mitochondria upon translation in the 


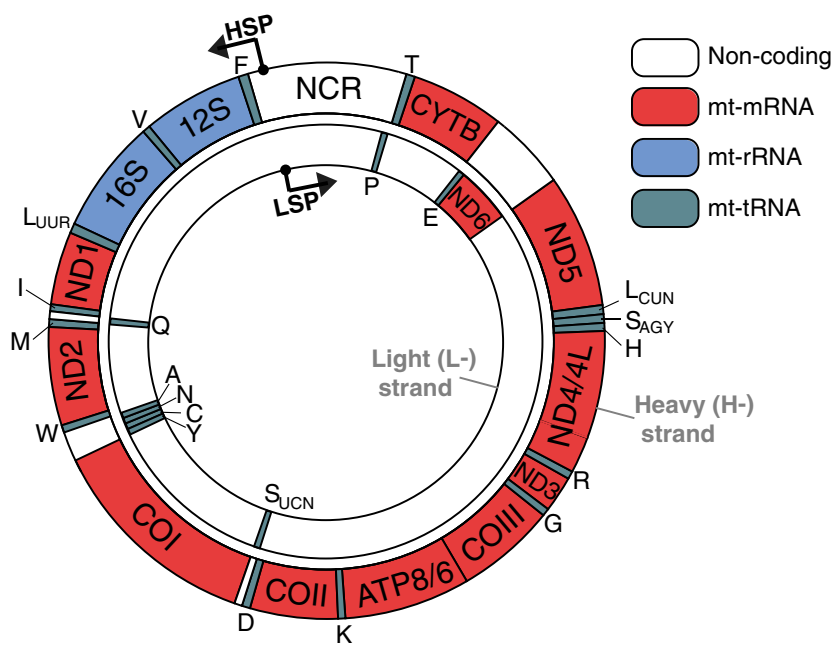

Fig. 1 Genetic map of the mitochondrial genome. The organisation of the genes on human mitochondrial genome is shown. The two strands of the human mtDNA, denoted light (L-) and heavy (H-), code for $2 \mathrm{mt}-$ rRNAs (blue), 22 mt-tRNAs (green) and 11 mt-mRNA molecules (red). The $11 \mathrm{mt}-\mathrm{mRNAs}$ encode 13 polypeptides of the electron transport chain and ATP synthase, where open reading frames of ATP8/ATP6 and ND4/ ND4L overlap and are contained within bicistronic mRNAs. The main non-coding region (NCR) contains promoters for transcription of the $\mathrm{H}$ strand and L-strand, HSP and LSP, respectively

cytosol. Based on the literature, evidence from studies of human mitochondrial proteomes (Pagliarini et al 2008; Smith et al 2012) and our unpublished predictions, we estimate that 250-300 nuclear-encoded proteins are dedicated to serve mitochondrial gene expression.

Mutations associated with mitochondrial disease are located either within nDNA or mtDNA. Most mitochondrial diseases are early onset, multi-systemic (affecting the brain, heart, skeletal muscle, liver and other organs) and often fatal. Inherited pathological mutations in genes encoding components involved in mitochondrial gene expression are generally associated with combined OXPHOS deficiencies affecting multiple enzymes involved in cellular respiration. However, isolated OXPHOS deficiencies, that affect only a specific biochemical activity of the OXPHOS system, have also been described for mutants in mitochondrial gene expression (e.g. Haack et al 2013). Many pathological mutations in the mtDNA-encoded tRNAs and rRNAs have been identified thus far (Yarham et al 2010), and given the size of mtDNA, detection of yet uncharacterised mutations is relatively straightforward. In contrast, the molecular diagnosis of patients with defects of mitochondrial gene expression due to mutations in nDNA is particularly difficult, mostly because of the high number of nuclear genes involved in these processes with only a fraction of them being characterised to date (Nicholls et al 2013; Boczonadi and Horvath 2014).

This review article describes how defects in mitochondrial RNA maturation are linked to human mitochondrial disease. We provide an overview of the mechanisms of mitochondrial transcript synthesis, endonucleolytic processing and posttranscriptional modifications of each class of mtRNA. This is followed by a description of a subset of nuclear-encoded factors involved in mtRNA metabolism, for which genetic variants impacting upon mitochondrial pathophysiology have been reported. Finally, we discuss primary pathological mtDNA mutations with recognised effects upon mt-tRNA nucleolytic processing and post-transcriptional maturation.

\section{Mechanisms of mitochondrial RNA maturation}

The generation of functional RNA molecules used for protein synthesis requires transcription, nucleolytic processing, posttranscriptional nucleotide modifications, polyadenylation of mt-mRNA and mt-tRNA-aminoacylation (Fig. 2). These steps are coordinated with RNA quality control, RNA stability regulation, biogenesis of the mitochondrial ribosome and translation activation (Fig. 2). However, the mechanistic details of how these processes occur are still unknown. In the first part of the review, before discussing human diseases associated with defects of mitochondrial RNA metabolism, we summarise the current available data on mtRNA metabolism.

\section{Generation of primary transcript and its endonucleolytic processing}

\section{Mitochondrial transcription}

Transcription of the human mitochondrial genome occurs on both DNA strands, is polycistronic, and produces long transcripts of mt-mRNAs and mt-rRNAs, usually interspersed with mt-tRNAs (Ojala et al 1981). Transcription of the light strand (L-strand, Fig. 1) template occurs from a single promoter (L-strand promoter, LSP) and this long transcript encodes the ND6 gene and eight mt-tRNAs (Figs. 1 and 3) (Montoya et al 1982, 1983). The majority of initiation events from LSP are believed to terminate some 200 bases downstream from the promoter, at "conserved sequence block 2" (CSB2) (Wanrooij et al 2010). This short RNA species is used to prime replication of the heavy DNA strand (H-strand, Fig. 1) as well as the synthesis of the D-loop, whose biogenesis and function is discussed in our recent review (Nicholls and Minczuk 2014). Classically, transcription of the H-strand template is initiated from two sites $(\mathrm{H}$-strand promoter 1 and 2, HSP1 and HSP2), located approximately 100 bases apart in the non-coding region (NCR) (Montoya et al 1982, 1983; Chang and Clayton 1984). HSP1 is located just upstream of the mt-tRNA ${ }^{\text {Phe }}$ gene, and initiation from this site produces a short transcript consisting of the two ribosomal RNAs (12S and $16 \mathrm{~S}$ ) and $\mathrm{mt}-\mathrm{tRNA}{ }^{\mathrm{Val}}$, terminating at the $\mathrm{mt}$ tRNA $^{\text {Leu(UUR) }}$ gene. Transcription from HSP2, immediately upstream from the $12 \mathrm{~S}$ mt-rRNA gene, bypasses this 
Fig. 2 Mitochondrial RNA metabolism. The mitochondrial rRNAs (blue), mRNAs (red) and tRNAs (green) are transcribed from the L- and $\mathrm{H}$-strands as polycistronic units that undergo endonucleolytic processing. Following the liberation of the individual mt-mRNA, mt-rRNA and mt-tRNA transcripts, they undergo post-transcriptional modifications. Several nucleotides of mt-rRNAs are modified to facilitate mitoribosome biogenesis and function. A poly(A) tail is added to mt-mRNAs, with the exception of the L-strand-encoded ND6. Mt-tRNAs undergo extensive post-transcriptional nucleotide modification, in addition to a CCA trinucleotide synthesis at the 3 ' end, before being aminoacylated with a cognate amino acid. Decay and surveillance pathways have also been described for mammalian mtRNA

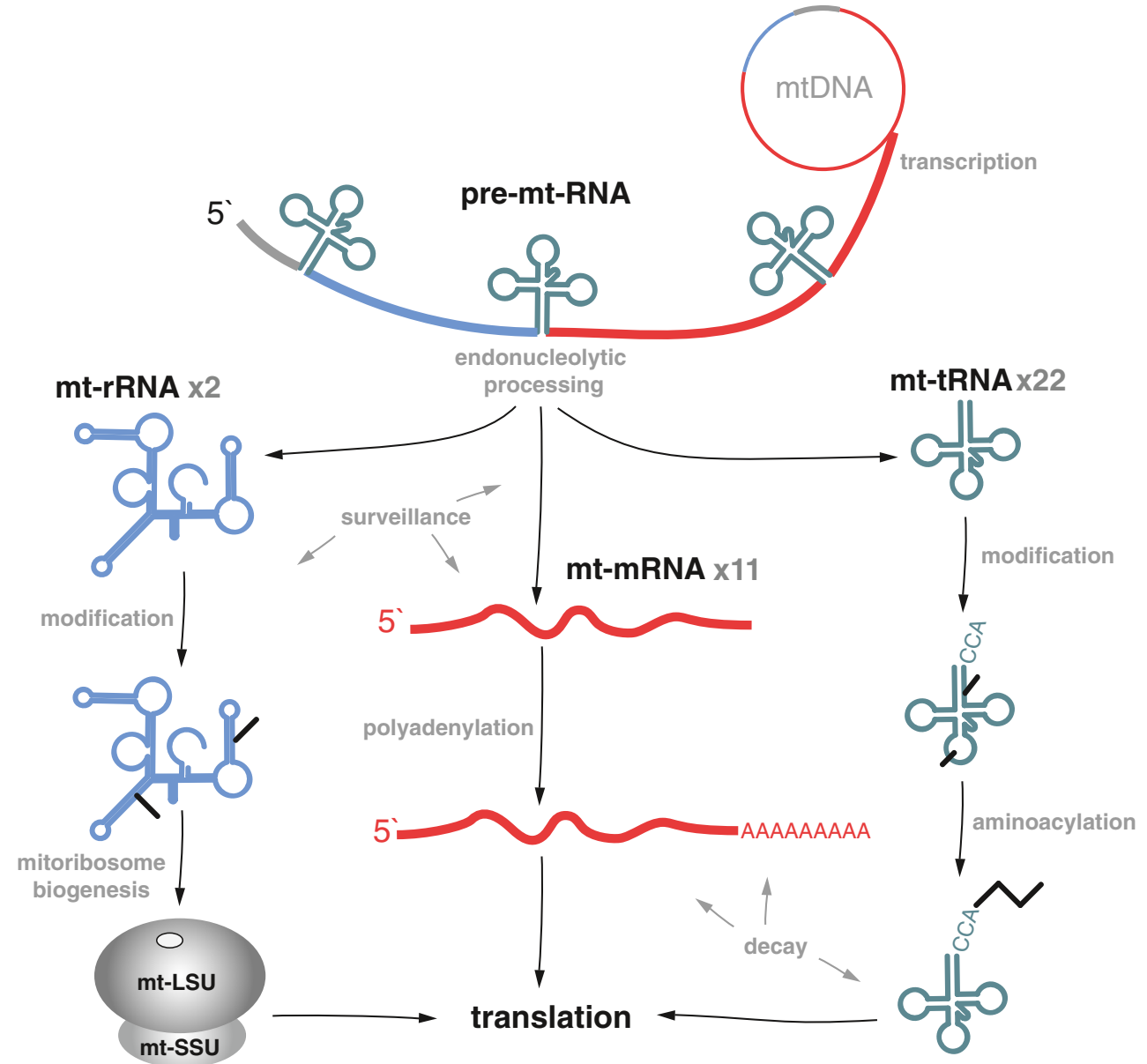

termination and produces an almost genome-length transcript of 2 mt-rRNAs, 12 mt-mRNAs and 14 mt-tRNAs. The mitochondrial transcription termination factor mTERF1 binds strongly to a tridecamer DNA sequence and has been proposed to terminate $\mathrm{H}$-strand transcription at the $\mathrm{mt}$ tRNA ${ }^{\text {Leu(UUR) }}$ gene (Christianson and Clayton 1988; Kruse et al 1989; Fernandez-Silva et al 1997). However, this was brought into doubt by the discovery that a mouse knockout of mTERF1 had normal H-strand transcription (Terzioglu et al 2013). It has been suggested that mTERF1 may actually serve to terminate the L-strand transcript, preventing the formation of antisense mt-rRNA species. The existence of HSP2 as a functional promoter in vivo is also questionable as transcription from this site is not readily detectable using established in vitro transcription systems (Litonin et al 2010). It may be the case, therefore, that only LSP and HSP1 (indicated as HSP on Fig. 1) are responsible for the transcription of all mitochondrially-encoded transcripts.

The basal protein machinery necessary for mitochondrial transcription has been well studied in humans, where RNA synthesis is performed by a single-subunit mitochondrial RNA polymerase, POLRMT, that shares homology with the RNA polymerases of the T-odd phages T3 and T7 (Masters et al 1987). POLRMT was identified through its homology with its yeast counterpart (Tiranti et al 1997). Later two homologues of the yeast mitochondrial transcription factor, mtTFB, were identified and named TFB1M and TFB2M (Falkenberg et al 2002; Cotney and Shadel 2006). Both contain an rRNA methyltransferase-like fold (Shutt and Gray 2006). TFB2M has been found to be necessary for transcription, and so appears to be the functional homologue of yeast mtTFB (Falkenberg et al 2002; Litonin et al 2010). TFB1M, on the other hand, appears to have mainly retained its dimethyltransferase function (see below) (Seidel-Rogol et al 2003; Metodiev et al 2009). Transcription in human mitochondria also requires mitochondrial transcription factor $\mathrm{A}$ (TFAM) (Falkenberg et al 2002; Shi et al 2012). The ability of TFAM to activate transcription is dependent upon a Cterminal tail, which is absent from its yeast homologue, Abf2p (Dairaghi et al 1995; Garstka et al 2003). Consistent with this, Abf2p is not required for yeast mitochondrial transcription, and is only involved in DNA packaging (Diffley and Stillman 1991; Parisi et al 1993).

In addition to these core factors, other proteins implicated in mitochondrial transcription include the transcription elongation factor TEFM and the large mitoribosomal subunit 
protein MRPL12. Acting in complex with POLRMT, TEFM is necessary for processivity of the polymerase and for increasing transcription rates by preventing a termination event at CSB2 (Minczuk et al 2011; Agaronyan et al 2015; Posse et al 2015). MRPL12 has also been found to bind POLRMT, and stimulate transcription in in vitro reactions (Wang et al 2007). This stimulatory effect was not observed in a later study from another group (Litonin et al 2010).

\section{Nucleolytic processing of mitochondrial precursor RNA}

Transcription of mtDNA results in polycistronic RNA molecules (Fig. 3). Most of the mt-mRNA or mt-rRNA-coding regions are separated by mt-tRNAs, which upon excision generate RNA products for translation or assembly into ribosomes (Anderson et al 1981; Ojala et al 1981). This processing mechanism is referred to as the 'tRNA punctuation model'. RNase $\mathrm{P}$ and RNase $\mathrm{Z}$ (elaC homolog 2 (ELAC2)) are the two main factors involved in mt-tRNA excision.

The RNase P enzyme is responsible for the $5^{\prime}$ end endonucleolytic cleavage of mt-tRNA precursors. Unlike the previously characterised RNase P enzymes, the mitochondrial counterpart contains no catalytic RNA component. Instead, it is composed of three multifunctional mitochondrial RNase P proteins, MRPP1 (TMRT10C or RG9MTD1), MRPP2 (HSD17B10, SDR5C1) and MRPP3 (Holzmann et al 2008). MRPP1 is a $\mathrm{m}^{1} \mathrm{G} 9$-methylase, whereas MRPP2 is a dehydrogenase also involved in isoleucine metabolism and other cellular functions (Yang et al 2005). MRPP1 and MRPP2 form a subcomplex that also participates in mt-tRNA modification (Vilardo et al 2012) (see below). MRPP3 is responsible for hydrolysis of the RNA phosphodiester bond (Rossmanith and Holzmann 2009). Knockdown of the different protein components of the mitochondrial RNase $\mathrm{P}$ all cause an accumulation of precursor RNA molecules (Holzmann et al 2008). Also, MRPP1 or MRPP3 knockdown reduced steady state levels of mature mt-tRNAs and some mt-mRNAs, which had a detrimental effect on mitochondrial translation (Sanchez et al 2011).

RNase Z, encoded by $E L A C 2$, is an endonuclease that completes the excision of mt-tRNAs from the primary transcript at the $3^{\prime}$ end. Human ELAC2 has been identified by homology to the bacterial counterpart elaC. There are two human genes encoding orthologs of elaC: ELAC1 and ELAC2. ELAC1 encodes a short form of RNase Z, localised in the cytosol (Rossmanith 2011), whereas ELAC2 encodes a long form of RNase $\mathrm{Z}$ and is restricted to eukaryotes. Alternative translation initiation of ELAC2 mRNA generates two products, of which only the longer form localises to mitochondria. In vitro, ELAC2 shows catalytic activity on both nuclear and mitochondrial pre-tRNAs (Rossmanith 2011). Knockdown of the protein causes the accumulation of mt-tRNA precursors (Brzezniak et al 2011; Sanchez et al 2011).

Other proteins have been recently implicated in precursor RNA processing in mitochondria. G-rich sequence factor 1, GRSF1, is an RNA-binding protein that co-localises with newly synthesised transcripts in mitochondrial foci named "RNA granules" (Antonicka et al 2013; Jourdain et al 2013). A decrease in some mature mitochondrial transcripts upon GRSF1 knockdown and co-localisation of GRSF1 with MRPP1 in RNA granules suggested a possible cooperative role in precursor RNA processing (Jourdain et al 2013). The discovery of RNA granules has catalysed further research on these structures, indicating very recently that they are central for post-transcriptional RNA maturation and the biogenesis of mitochondrial ribosomes (see below) (Antonicka and Shoubridge 2015; Jourdain et al 2015).

Pentatricopeptide-repeat containing (PPR) domain family of proteins member 1, PTCD1 (Small and Peeters 2000), is predicted to have a role in mtRNA metabolism. It has been suggested that this protein plays a role in coordinating $3^{\prime}$
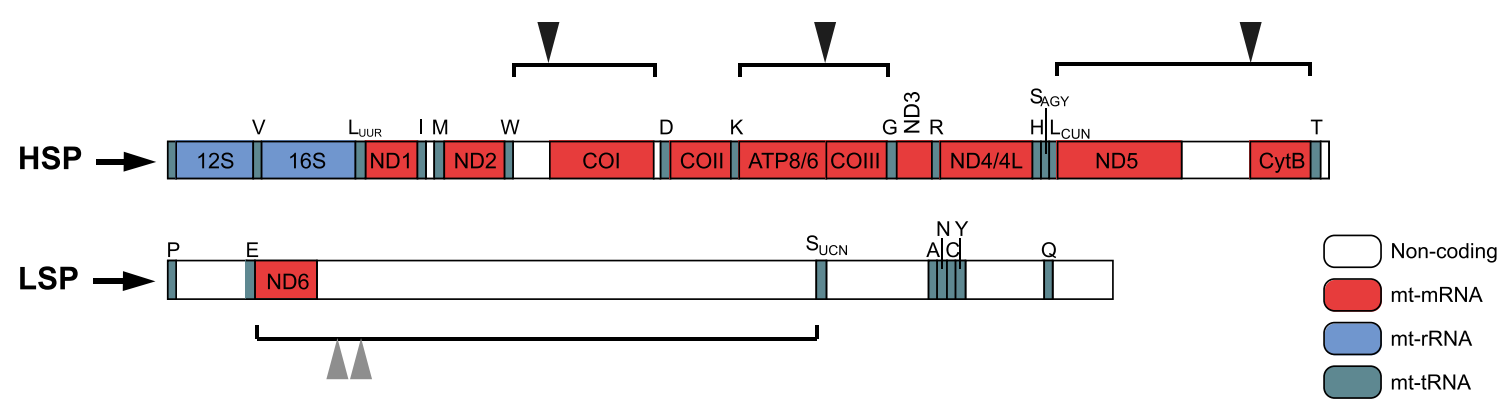

Fig. 3 Polycistronic transcription units in mitochondria. Polycistronic precursor mitochondrial transcripts are shown. The transcript from LSP contains only the coding sequences for the ND6 subunit of complex I and eight mt-tRNAs. All other coding sequences are produced by transcription from HSP. With some exceptions (triangles), mt-rRNAs (blue) and mt-mRNAs (red) are punctuated with mt-tRNAs (green).
The endonucleolytic processing of mt-tRNA liberates most of the mtmRNAs and the two mt-rRNAs. The enzymatic machinery responsible for the processing at the non-canonical sites, not punctuated with mttRNAs, is not well investigated. ND6 mRNA shows multiple 3' ends: either $500 \mathrm{nt}$ (Slomovic et al 2005) or $30 \mathrm{nt}$ (Mercer et al 2011) downstream of the translation termination codon 
processing of mt-tRNAs and that there is a direct interaction between PTCD1 and ELAC2 (Sanchez et al 2011). Additional studies have suggested a role for PTCD1 in controlling the levels of both leucine mt-tRNAs (Rackham et al 2009), which might have a role in adaptation of mitochondria to amino acid starvation (Schild et al 2014).

There are various sites in mitochondrial polycistronic transcripts that are not consistent with the 'tRNA punctuation model' and are cleaved independently of the presence of mttRNAs (Fig. 3). These include: (i) the bicistronic ATP8/6COIII, (ii) the $5^{\prime}$ end of COI, (iii) the $5^{\prime}$ end of CytB, and (iv) the 3' end of ND6 (Anderson et al 1981; Temperley et al 2010). There are no obvious sequence motifs within the proximal regions of $\mathrm{COI}$, $\mathrm{COIII}$ or $\mathrm{CytB}$ that could serve as recognition sites for cleavage. Knockdown of ELAC2 and the components of RNase P show no effect on the levels of these non-conventional cleavage sites (Brzezniak et al 2011). PTCD2 has been implicated in the cleavage of the junction between ND5 and CytB (Fig. 3) as a PTCD2 knockout mouse accumulates the ND5-CytB precursor and do not properly assemble complex III (where CytB is the catalytic core component) (Xu et al 2008a). More recently, an RNA granule protein, FASTKD5 (Fas-activated serine/threonine (FAST) kinase domain containing protein 5 ), has been suggested to be required for maturing precursor of COI mRNA (Antonicka and Shoubridge 2015). However, the exact role of these proteins in relation to mtRNA endonucleolytic processing remains to be determined.

\section{Mitochondrial mRNA maturation and maintenance}

\section{Mitochondrial $m R N A$ polyadenylation}

Mitochondrial mRNAs liberated by mt-tRNA excision undergo further maturation steps, however, the scope of these events is very limited when compared to the nuclear-encoded mRNAs. Mitochondrial mt-mRNAs do not contain the 5' cap modification nor introns to be spliced. Most mt-mRNAs are polyadenylated on their $3^{\prime}$ ends, with poly(A) tails being much shorter (approximately 45-55 nt) than the ones found on the nDNA-encoded mRNAs. Poly(A) tails have not been detected in the case of ND6 mt-mRNA and the ND5 transcript is oligoadenylated (or not adenylated at all) (Temperley et al 2010).

Mitochondrial poly(A) tails are synthesised by a noncanonical poly (A) polymerase (mtPAP) that localises to the mitochondrial RNA granules (Tomecki et al 2004; Nagaike et al 2005; Bai et al 2011; Wilson et al 2014). Knockdown of mtPAP causes shortening of poly(A) tails and disruption of the respiratory function (Nagaike et al 2005). Although mtPAP can use all four nucleoside triphosphates (NTPs) as substrates, it is most active with ATP (Bai et al 2011).

Phosphodiesterase 12 (PDE12), a mitochondrial 2'- and 3'phosphodiesterase (Poulsen et al 2011; Rorbach et al 2011), has been shown to specifically remove poly(A) tails from mtmRNAs in vitro and in cultured cells upon overexpression (Rorbach et al 2011). The $3^{\prime}$-to-5' deadenylase activity of PDE12 requires a free 3 '-OH group and prefers homopolymers of adenines.

The exact role for mitochondrial poly(A) tails is still unclear (Rorbach et al 2014a). However, seven out of 13 mtDNA-derived ORFs do not encode complete stop codons for the termination of translation. In these cases, the mtmRNAs are immediately adjacent to mt-tRNA genes and the excision of mt-tRNA leaves behind an incomplete stop codon of 'U' or 'UA' (Anderson et al 1981). Polyadenylation generates a complete 'UAA' stop codon (Ojala et al 1981).

Polyadenylation has different effects on the stability of various mitochondrial transcripts. It generally decreases the stability of COI, COII, COIII and ATP6/8, and increases the stability of ND1 and ND2. Polyadenylation also causes the increase in stability of ND3, ND4/4 L, ND5 and CytB to a lesser extent (Rorbach et al 2011; Wydro et al 2010; Rorbach and Minczuk 2012). The mechanism of this transcript-specific role of polyadenylation remains to be elucidated.

Whether poly(A) tail addition is directly involved in regulating mitochondrial translation in the mitochondria is still an unresolved issue. Overexpression of mitochondrial deadenylase PDE12 or mitochondrially targeted cytosolic poly(A)-specific ribonuclease (PARN) caused strong inhibition of protein synthesis. This is further supported by the observation that targeting cytosolic poly(A)-binding protein 1 (PABPC1) into the mitochondria inhibited translation (Wydro et al 2010). However, inactivation of mitochondrial protein LRPPRC (see the next section) in a mouse knockout model or loss-of-function mutations in MTPAP (Wilson et al 2014) (described below) were associated with the loss of mtmRNA poly(A) tails with no universal effect on translation. The latter result suggests that translation of some mitochondrial transcripts can be effective even in the absence of mtmRNA polyadenylation.

\section{Mitochondrial mRNA stability, decay and surveillance}

Regulation of RNA stability and turnover are important steps in post-transcriptional control of gene expression and are usually mediated by protein complexes. Several proteins have been implicated in these processes in human mitochondria.

The human Suv3 protein (hSuv3p, Suppressor of Var1, 3like protein 1, SUPV3L1) is an NTP-dependent helicase that localises to the mitochondria. The SUPV3L1 gene undergoes alternative splicing and contains more than one translation initiation site, the latter observed for a number of mitochondrially-targeted proteins (Minczuk et al 2005; Szczesny et al 2007; Kazak et al 2013). At least one of the isoforms localises to the mitochondrial matrix (Minczuk et al 2002). hSuv3p is able to unwind multiple DNA and RNA 
substrates (Minczuk et al 2002; Shu et al 2004). It has been suggested that hSuv3p is involved in mtRNA degradation of aberrant mtRNA (Khidr et al 2008; Szczesny et al 2010) and plays a role in the decay pathway of properly processed RNA molecules (Szczesny et al 2010).

Polynucleotide phosphorylase, PNPase (encoded by PNPT1), is capable of $3^{\prime}$-to-5' phosphorolysis and 5'-to-3' polymerisation of RNA (Wang et al 2009). PNPase has been reported to form complexes localised in the matrix, although mitochondrial inner membrane space localisation has also been observed (Chen et al 2006). PNPase has been attributed to numerous roles in mtRNA metabolism, including degradation, polyadenylation and RNA import (Chen et al 2006; Slomovic and Schuster 2008; Borowski et al 2013; Chujo et al 2012).

Recent evidence indicates that PNPase co-localises with hSuv3p in the mitochondria in distinctive RNA-positive foci and works in collaboration to facilitate RNA degradation (Szczesny et al 2010). This suggests that there might be two pools of PNPase, in the intermembrane space and in the matrix (Borowski et al 2013). In vitro reconstitution experiments have indicated that the hSuv3-PNPase complex degrades RNA substrates in the $3^{\prime}$-to-5' direction (Wang et al 2009; Lin et al 2012).

The RNA exonuclease 2, REXO2, is an additional mitochondrial nuclease potentially involved in mtRNA metabolism. It is a homotetrameric $3^{\prime}$-to-5' exonuclease that degrades oligonucleotides and is localised to both the intermembrane space and the matrix (Bruni et al 2013). Given that the PNPase-hSuv3p complex is expected to degrade RNA producing oligo-ribonucleotides, it is possible that they form the substrate of REXO2 for later stages of the decay pathway. $\mathrm{REXO} 2$ has also been proposed to have a function in recycling mono-ribonucleotides (Bruni et al 2013).

RNA-binding proteins are often key regulators of the posttranscriptional life of transcripts. Two mitochondrial RNAbinding proteins, LRPPRC and SLIRP, have been recently associated with mtRNA metabolism. LRPPRC is a highly abundant $130 \mathrm{kDa}$ leucine-rich PPR containing protein, and is predominately localised in the mitochondrial matrix (Sterky et al 2010). Inactivation of LRPPRC results in a severe depletion of mt-mRNA, but not mt-rRNA or mt-tRNA, and a consequential impairment in translation and in assembly of mitochondrially-encoded OXPHOS subunits (Gohil et al 2010; Sasarman et al 2010a; Sondheimer et al 2010; Ruzzenente et al 2012; Mourier et al 2014). Stem-loop interacting RNA binding protein, SLIRP, is essential for mtRNA maintenance (Baughman et al 2009) and exists in a high-molecular-weight complex with LRPPRC (Sasarman et al 2010b). The LRPPRC-SLIRP complex regulates mtmRNA stability and translation without directly associating with ribosomes or POLRMT (Ruzzenente et al 2012; Harmel et al 2013). Knockdown of one of the two proteins caused a decrease in endogenous levels of the other, suggesting strong interdependence (Chujo et al 2012; Ruzzenente et al 2012). The LRPPRC-SLIRP complex has been recently associated with a role in mt-mRNA polyadenylation. Inactivation of either LRPPRC or SLIRP resulted in a reduction in polyadenylated mt-mRNAs, with an in vitro stimulatory effect of LRPPRC-SLIRP, but not SLIRP alone, on polyadenylation by mtPAP (Chujo et al 2012; Wilson et al 2014). It has been suggested that LRPPRC plays a role in stabilising a pool of translationally-inactive mt-mRNAs that are not associated with ribosomes (Ruzzenente et al 2012). The LRPPRC-SLIRP complex may also function by binding to the mt-mRNA and preventing the formation of secondary structures making the $3^{\prime}$-terminal available for polyadenylation. This activity of the complex might also be involved in suppressing PNPase-hSuv3-mediated mt-mRNA degradation (Chujo et al 2012).

\section{Mitochondrial rRNA maturation}

Human mitochondrial ribosomes are composed of two unequally sized subunits (Brown et al 2014; Greber et al 2014; Kaushal et al 2014; Amunts et al 2015). The small 28S subunit (mtSSU) plays a role in catalysing the peptidyl-transferase reaction, while the large 39S subunit (mtLSU) is involved in mt-mRNA binding and decoding. These two subunits are composed of $12 \mathrm{~S}$ mt-rRNA (mtSSU) and 16S mt-rRNA (mtLSU) and ribosomal proteins. The biogenesis of the mitochondrial ribosome is a complex process entailing a number of auxiliary factors (Rorbach et al 2012; Dalla Rosa et al 2014). Maturation of mt-rRNA through a number of posttranscriptional nucleotide modifications is necessary for correct folding, stability and ribosome assembly (Decatur and Fournier 2002). However, while cytosolic rRNAs have over 200 modifications and bacterial rRNAs over 30, only nine modified nucleotides have been identified in mt-rRNAs (Piekna-Przybylska et al 2008).

\section{Maturation of $12 S$ mt-rRNA}

Mt-tRNA cleavage from the mitochondrial $\mathrm{H}$-strand precursor liberates full-length $12 \mathrm{~S}$ and $16 \mathrm{~S}$ mt-rRNAs without a requirement of any further nucleolytic processing events. Five nucleotide modifications have been identified in the mammalian 12S mt-rRNA, with one methylated uracil (12S: $\mathrm{m}^{5} \mathrm{U} 429$, mtDNA position: 1076), two cytosine methylations (12S: $\mathrm{m}^{4} \mathrm{C} 839$ and $\mathrm{m}^{5} \mathrm{C} 841$, mtDNA positions: 1486 and 1488, respectively) and two dimethylated adenosines (12S: $\mathrm{m}^{6} \mathrm{~A} 936$ and $\mathrm{m}_{2}^{6} \mathrm{~A} 937$, mtDNA positions: 1583 and 1584) (Baer and Dubin 1981). Only two of the proteins responsible for these post-transcriptional nucleotide modifications have been characterised to date (Fig. 4). 


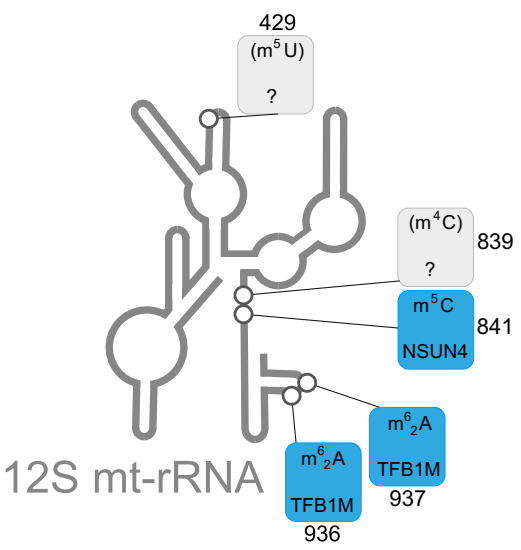

Fig. 4 Post-transcriptional modifications of mitochondrial ribosomal RNA. Schematics of the secondary structure of $12 \mathrm{~S}$ and $16 \mathrm{~S} \mathrm{mt-}$ rRNAs, indicating post-transcriptionally modified bases (circles) is shown. The details of the chemical modification and enzyme responsible (if known) for each mt-rRNA position is given in boxes, indicating the

TFB1M is responsible for dimethylation of two highly conserved adjacent adenines in a stem-loop structure near the $3^{\prime}$ end of the $12 \mathrm{~S}$ mt-rRNA, m ${ }_{2} \mathrm{~A} 936$ and $\mathrm{m}^{6}{ }_{2} \mathrm{~A} 937$ (Seidel-Rogol et al 2003; Metodiev et al 2009). In bacteria, this region contains the mRNA decoding centre and the binding site for the large subunit $(\mathrm{Xu}$ et al 2008b). The lack of TFB1M causes a dramatic decline of $12 \mathrm{~S}$ mt-rRNA levels, leading to a deficiency of assembled mtSSU and results in a severe impairment of mitochondrial translation (Metodiev et al 2009).

Another protein that plays a role in $12 \mathrm{~S}$ mt-rRNA maturation is NSUN4 (NOP2/Sun domain containing family, member 4), which has been suggested to have a dual function. In a complex with MTERF4, it plays a role in ribosome assembly regulation (Camara et al 2011; Spahr et al 2012; Yakubovskaya et al 2012). However, the NSUN4 protein on its own is capable of $\mathrm{m}^{5} \mathrm{C} 841$ methylation of the $12 \mathrm{~S} \mathrm{mt}$ rRNA. It has been speculated that $\mathrm{m}^{5} \mathrm{C} 841$ is involved in stabilisation of mt-rRNA folding, in cooperation with $\mathrm{m}^{4} \mathrm{C} 839$ methylation. The methyltransferases required for methylation of $12 \mathrm{~S}$ mt-rRNA positions $\mathrm{C} 481$ and U429 remain unidentified (Fig. 4).

\section{Maturation of $16 S \mathrm{mt}-\mathrm{rRNA}$}

Four nucleotides are modified in the mammalian $16 \mathrm{~S}$ mtrRNA: two ribose methylations of guanosine (16S: Gm1145 and Gm1370, mtDNA positions: 2815 and 3040), one ribose methylation of uridine (16S Um1369, mtDNA position 3039), and one pseudouridylated base (16S: Psi1397, mtDNA position: 3067) (Dubin and Taylor 1978; Ofengand and Bakin 1997). Mitochondrial rRNA methyltransferase 1, MRM1, is responsible for 2'-O-ribose methylation of $16 \mathrm{~S}$ mt-rRNA position $\mathrm{Gm} 1145$ and is present in mitochondrial RNA granules

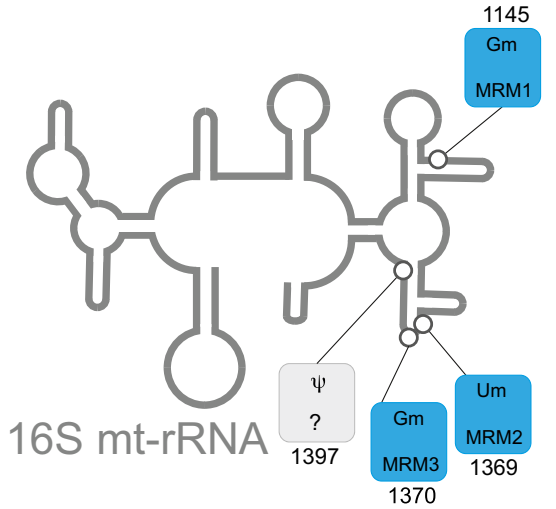

mt-rRNA base position number next to each box. The chemical modifications identified in mammalian species other than human are in brackets. Colour coding: blue, enzyme responsible for particular modification has been identified; grey, modifying enzyme has not been identified

(Lee et al 2013; Lee and Bogenhagen 2014; Rorbach et al 2014b). In yeast mitochondria, this methylation is crucial for the stability of the large ribosomal subunit and for ribosomal function (Sirum-Connolly and Mason 1993), however the role of this modification in human 16S mt-rRNA has not been investigated. Two other methylated nucleotides of the $16 \mathrm{~S}$ mt-rRNA, Um1369 and Gm1370 are localised in the A-loop, an essential component of the peptidyl transferase centre of the large subunit rRNA and are involved in the interaction with the aminoacyl site of the mt-tRNA (Decatur and Fournier 2002). These sites are modified by MRM 2 and MRM3 (also known as RNMTL1), respectively (Lee et al 2013; Lee and Bogenhagen 2014; Rorbach et al 2014a). Both enzymes are localised in mitochondrial RNA granules and are indispensable for correct mitochondrial translation and OXPHOS function. Ineffective translation in MRM2 and MRM3-depleted cells stems from aberrant assembly of mtLSU (Rorbach et al 2014b). It remains to be established, however, whether the presence of MRM2/MRM3 or rather the presence of the actual modification of $16 \mathrm{~S}$ mt-rRNA is crucial for mitochondrial ribosome biogenesis. The enzyme responsible for pseudouridylation of the 16S mt-rRNA is still unknown (Fig. 4).

\section{mt-tRNA maturation}

The release of mt-tRNAs from a polycistronic primary transcript does not mark the end of their maturation process (Fig. 2). Instead, numerous post-transcriptional modifications are utilised to form the cloverleaf structure resulting in a stable and correctly functioning tRNA (Helm et al 1999). A great range of chemical diversity exists in the modifications found to mt-tRNAs, with bases undergoing methylations, isomerisations, thiolations, formylations, and ribosylations, along with 
others, by a multitude of nuclear factors. The impact of a tRNA modification can be broadly divided into those that confer structural stability and correct folding, and those that assist proper tRNA function via altering tRNA interaction with other factors.

Whilst many unmodified tRNAs fold into structures that are in approximately the correct conformation (Sampson and Uhlenbeck 1988; Harrington et al 1993), unmodified mitochondrial tRNAs transcribed in vitro have been demonstrated to fold into a range of non-functional secondary structures (Helm et al 1998). Modifications towards the core of the tRNA typically play a role in its structure and stability, often through the modulation of the rigidity of particular domains. For example, saturation of the pyrimidine ring of uracil to form dihydrouridine results in a greater range of conformational flexibility (Dalluge 1996), while the introduction of pseudouridine, through the isomerisation of uridine, acts to increase the structural rigidity of the tRNA (Davis 1995). Base methylation can also influence tRNA structure in a number of ways. For example, the methylation of adenine in position 9 (A9) in human mt-tRNA ${ }^{\text {Lys }}$ by the RNase P subcomplex of MRPP1 and MRPP2 (HSD17B10) (Vilardo et al 2012) impacts on tRNA structure. Unmodified mttRNA ${ }^{\text {Lys }}$ folds into a non-functional extended hairpin structure, which is not recognised by its cognate lysyl-tRNA synthetase (Helm et al 1998; Sissler et al 2004). The introduction of $\mathrm{m}^{1} \mathrm{~A} 9$ alone into $\mathrm{mt}-\mathrm{tRNA} \mathrm{A}^{\mathrm{Lys}}$ is sufficient to favour the formation of the canonical cloverleaf structure by disrupting the A9-U64 Watson-Crick base pair in the extended hairpin (Helm et al 1999). However, the stabilising effects of the $N^{1}$ methylation of adenine have also been identified, on the Tloop at position 58 , catalysed in human mitochondria by tRNA methyltransferase TRMT61B (Chujo and Suzuki 2012).

Modifications at tRNA residue positions 34 and 37 are important for maintaining translation accuracy and fidelity, representing the greatest chemical diversity found in a tRNA's modification profile. One or both of these positions are modified in almost all tRNAs so far studied. The translation of an mRNA into its corresponding polypeptide chain is dependent on the precise interactions between the three bases (referred to as 1,2 and 3) of the mRNA's triplet codon and the triplet anticodon of the cognate tRNA (at positions 36, 35 and 34). However, owing to degeneracy of the genetic code, multiple codons must be recognised by a single tRNA. Degenerate codons contain identical residues in positions 1 and 2 and are expanded through variability in position 3 . To accomplish this, the interactions between residues 3 and 34 are non-standard, allowing for a much greater range of possible base pairs, a characteristic referred to as 'wobble'. Position 34, or the wobble base, is often occupied by a uridine, capable of base pairing with any of the four bases due to enhanced conformational flexibility within the anticodon loop. This scenario is sufficient for the majority of codons in which the residue in position 3 is entirely degenerate. However, in a number of cases, the presence of a purine or a pyrimidine in position 3 produces codons for different amino acids. The increase in discrimination by the wobble base required for accurate decoding is achieved through its post-transcriptional modification (Johansson et al 2008). For example, the formation of the $\tau \mathrm{m}^{5}\left(\mathrm{~s}^{2}\right) \mathrm{U}$ modification by the concerted action of GTP binding protein 3, GTPBP3, (Villarroya et al 2008), MTO1 (mitochondrial tRNA translation optimisation 1) (Li et al 2002) and MTU1 (mitochondrial tRNA-specific 2-thiouridylase, TRMU) (Yan et al 2006a), greatly favours base pairing with purines and prevents codon misreading (Yokoyama et al 1985) as has been demonstrated for human mttRNA $^{\text {Leu(UUR) }}$ (Kirino et al 2004). The recognition of purines at position 3 is also exemplified by the formylation in mt-tRNA ${ }^{\mathrm{Met}}$, the resulting $\mathrm{f}^{5} \mathrm{C} 34$ allows the tRNA to read the AUA as well as AUG codons (Bilbille et al 2011). Whilst stringent selection of the correct cognate tRNA is key to ensuring accuracy, a stable codonanticodon interaction is critical for translation efficiency. For this reason, tRNAs with anticodons bearing $U$ and A in position 36 often require modification at the adjacent position 37 (Lamichhane et al 2013a). For example, in mammalian mitochondria position 37 contains $N^{6}$ threonylcarbamoyladenosine $\left(\mathrm{t}^{6} \mathrm{~A} 37\right)$ and N6isopentenyladenosine ( $\left.\mathrm{i}^{6} \mathrm{~A} 37\right)$, catalysed by TRIT1 (tRNA isopentenyltransferase 1) in human cells (Yarham et al 2014) and further modified by CDK5RAP1 (Cyclindependent kinase 5 regulatory subunit associated protein 1) to form $\mathrm{ms}^{2} \mathrm{i}^{6} \mathrm{~A} 37$ (Reiter et al 2012). A guanosine residue may also be present at position 37 in human $\mathrm{mt}-$ tRNAs, which is often methylated to form $N^{1}$ methylguanosine ( $\left.\mathrm{m}^{1} \mathrm{G} 37\right)$ by TRMT5 (Brule et al 2004). The $\mathrm{m}^{1} \mathrm{G}$ modification disrupts the formation of WatsonCrick base pairing, therefore blocking potential base pairing between G37 and the mRNA to prevent frameshifting (Urbonavicius et al 2001; Urbonavicius 2003). By interfering with base pairing, $m^{1} \mathrm{G} 37$ may also prevent interactions with neighbouring nucleotides on the other side of the anticodon loop to aid in the formation of the canonical loop structure required for codon-anticodon interactions (Cabello-Villegas et al 2002).

Lastly, post-transcriptional modifications of tRNAs may assist in translational fidelity through ensuring correct aminoacylation. The recognition of a tRNA by its cognate tRNA-aminoacyl synthetase depends on the identification of particular nucleotides and structural motifs, predominantly within the anticodon loop and the acceptor helix, such as the discriminator base at position 73 , and the $5^{\prime}$ terminal CCA added post-transcriptionally by TRNT1 
(Nagaike et al 2001). The majority of modifications are assumed to contribute to tRNA identity indirectly through the stabilisation of a recognised structural feature. However, a direct identity element role for a modified nucleotide, either as a recognition determinant as in $\Psi 35$ in yeast tRNA ${ }^{\text {Tyr }}$ (Bare and Uhlenbeck 1986), or an antideterminant as has been described for $\mathrm{m}^{1} \mathrm{G} 37$ in yeast tRNA $^{\text {Asp }}$ (Putz et al 1994), cannot be ruled out in human mitochondrial tRNAs.
A complete set of modifications for bovine mttRNAs, which share a high degree of structural and sequence similarity with human mt-tRNAs, have recently been described (Suzuki and Suzuki 2014). From this work, many human mt-tRNA modifying enzymes may be predicted, bringing us closer to a comprehensive modification profile for human mt-tRNAs (current status summarised in Fig. 5, expanded upon in Powell et al (2015) and Suzuki et al (2011).

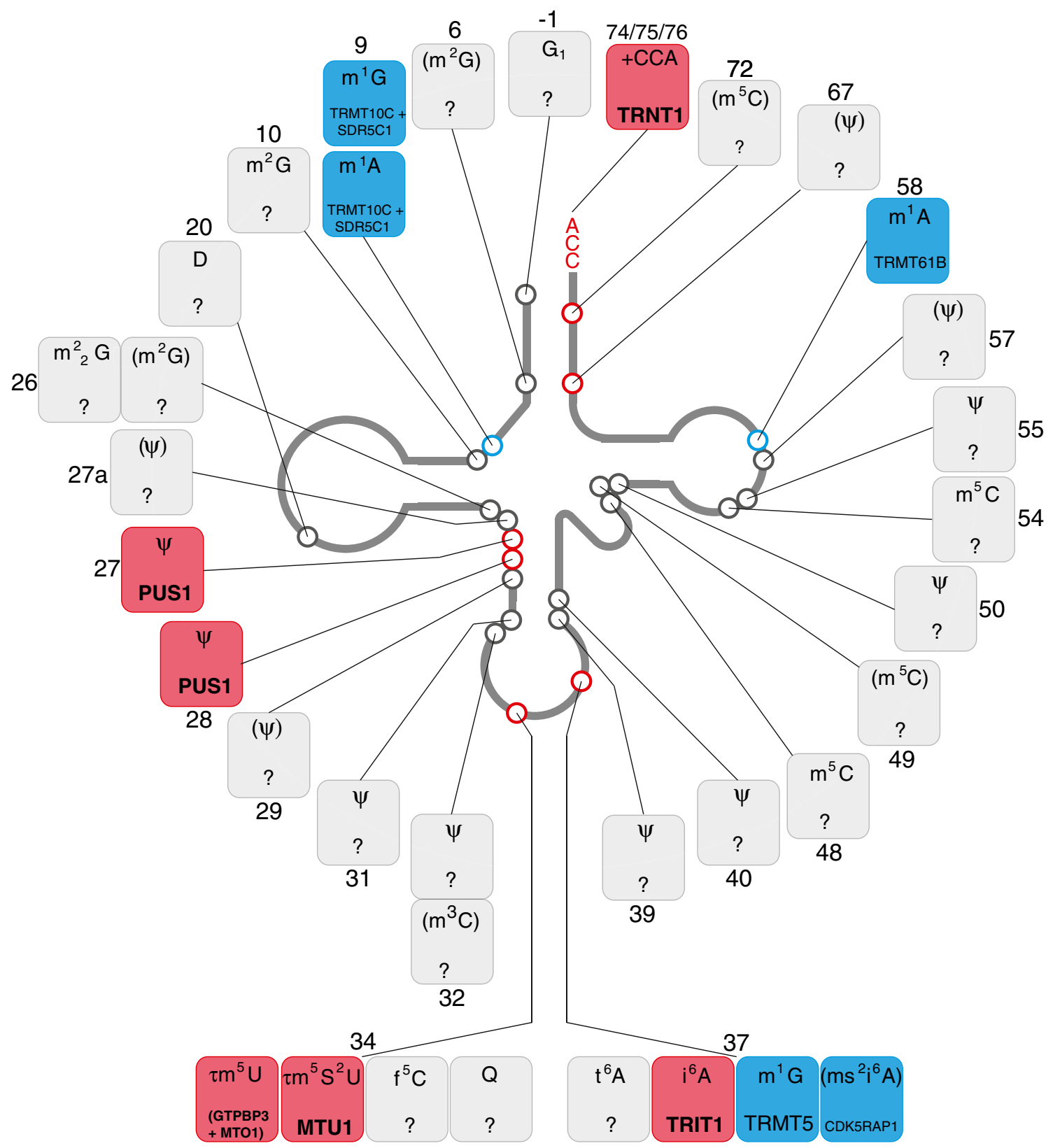

Fig. 5 Post-transcriptional modifications of mitochondrial transfer RNA and human disease. Schematics of the "clover leaf" secondary structure of a generic mitochondrial tRNA indicating post-transcriptionally modified bases (circles) is shown. The details of the chemical modification and the enzyme responsible (if known) for each mt-tRNA position is given in boxes, indicating the mt-tRNA base position number next to each box.

The chemical modifications identified in mammalian species other than human are in brackets. Colour coding: red, enzyme responsible for the modification has been associated with human disease; blue, enzyme responsible for particular modification has been identified; grey, modifying enzyme has not been identified 


\section{Human diseases associated with defects of mitochondrial RNA maturation}

\section{Defects of mt-pre-RNA processing}

\section{HSD $17 B 10$}

As discussed in Nucleolytic processing of mitochondrial precursor RNA, the mitochondrial RNase P complex consists of three protein components, MRPP1, 2 and 3. The exact role of MRPP2, also known as $17 \beta$-hydroxysteroid dehydrogenase type 10 (HSD17B10), in the RNase P complex is unknown. However, it is a multifunctional mitochondrial protein which, in addition to its functions in mtRNA maturation, catalyzes the 2-methyl-3-hydroxylbutyryl-CoA dehydrogenation (MHBD) reaction in isoleucine metabolism, converting 2methyl-3-hydroxybutyryl-CoA to 2-methyl-acetoacetyl$\mathrm{CoA}$, as well as playing a potential role in the pathogenesis of Alzheimer's disease (Chen and Yan 2007) (Table 1).

Patients in at least 19 independent families have been reported to carry pathogenic, X-linked mutations in HSD17B10 [MIM: 300256] (HSD17B10 is located at Xp11.2) (Zschocke 2012). Affected patients suffer from a progressive loss of cognitive and motor function, epilepsy, retinal degeneration and progressive cardiomyopathy, with lactic acidosis also a common presentation. Infantile onset is most common, with onset of symptoms following the first 6-18 months of life, resulting in death at age 2-4 years or later. A more severe neonatal form has been characterised with severe progressive cardiomyopathy with limited neurological presentation, resulting in early death (Perez-Cerda et al 2005). Due to the X-linked nature of inheritance, symptoms have been shown to vary between male and female patients carrying the same mutation in HSD17B10 (Perez-Cerda et al 2005).

The severity of clinical symptoms presenting in patients with mutations in HSD17B10 are suspected to be independent of relative residual MHBD activity in different mutant variant proteins (Rauschenberger et al 2010), and attempts at placing patients on isoleucine restricted diets have had mixed success at preventing further clinical deterioration (Zschocke et al 2000; Perez-Cerda et al 2005). Additionally, the neurodegenerative disorder experienced in patients with HSD17B10 deficiency is dissimilar to other disorders of isoleucine metabolism or other organic acidurias, and more closely resembles a primary mitochondrial disorder (Rauschenberger et al 2010). This evidence may suggest that the deficiency in MHBD activity of HSD17B10 may not be the primary cause of clinical presentation of the disease, and is instead linked to an independent mitochondrial dysfunction.

In a recent article, Deutschmann et al (2014) have suggested that the disorder associated with mutations in HSD17B10 may instead be linked to the role of HSD17B10 (MRPP2) in mtRNA endonucleolytic processing. In this study, patient fibroblasts harbouring a p.R130C mutation in HSD17B10, which causes infantile onset disease, were shown to have a lower residual protein level of HSD17B10 compared to controls, which was accompanied by a reduction in MRRP1 protein, but not MRPP3. The study showed there was impaired processing of the H-strand precursor mtRNA transcript, but not the L-strand, compared to controls. This deficiency in mtRNA processing may contribute to the mitochondrial disorder experienced in HSD17B10 patients.

Due to the multifunctional nature of the protein, it is possible that mutants at different sites within HSD17B10 may have independent effects on mtRNA processing and MHBD activity, which in turn may influence the clinical presentation and severity of the disorder.

\section{ELAC2}

Pathogenic mutations in the ELAC2 gene, which encodes the nuclease that cleaves $3^{\prime}$ off mt-tRNAs, have recently been identified [MIM: 605367] (Haack et al 2013). Initial exome sequencing of two unrelated probands who each exhibited a suspected infantile-onset mitochondrial disorder identified mutations in ELAC2 as the possible underlying defect. Further targeted sequencing of ELAC2 in 350 individuals with oxidative phosphorylation disorders identified two additional cases of genetic variation in ELAC2 in siblings of an unrelated family. In this study, a total of five individuals were identified across three independent families, harbouring either compound heterozygous or homozygous mutations in ELAC2.

Like many mitochondrial disorders, severity of disease progression varied among individuals, but all patients presented with some consistent clinical features. All individuals presented with poor growth, onset of infantile hypertrophic cardiomyopathy prior to 6 months and elevated lactate levels and associated (or consequent) alanine and occasional increase of glutamine and ammonia, consistent with a status of metabolic acidosis. Isolated complex I deficiency in skeletal muscle was observed in all patients, with one individual also exhibiting a complex IV deficiency. In four out of five individuals studied, a mild to marked developmental delay was also apparent. Two patients died before 12 months of age and a third died at the age of 4 years.

If variants in ELAC2 were indeed the underlying primary defect, it was expected that processing at sites $3^{\prime}$ to mt-tRNAs would be hindered due to lack of ELAC2 activity. All tRNAmRNA junctions expected to be cleaved by the ELAC2 protein showed accumulation in patient skeletal muscle, and, to a lesser extent, in patient fibroblasts, as assessed by qPCR. This was confirmed by RNA-Seq and northern blotting, consistent with the characterised RNase Z activity of ELAC2 in mitochondria. Notably, changes to steady state levels of correctly processed mt-tRNAs, mt-rRNAs and mt-mRNAs were not 


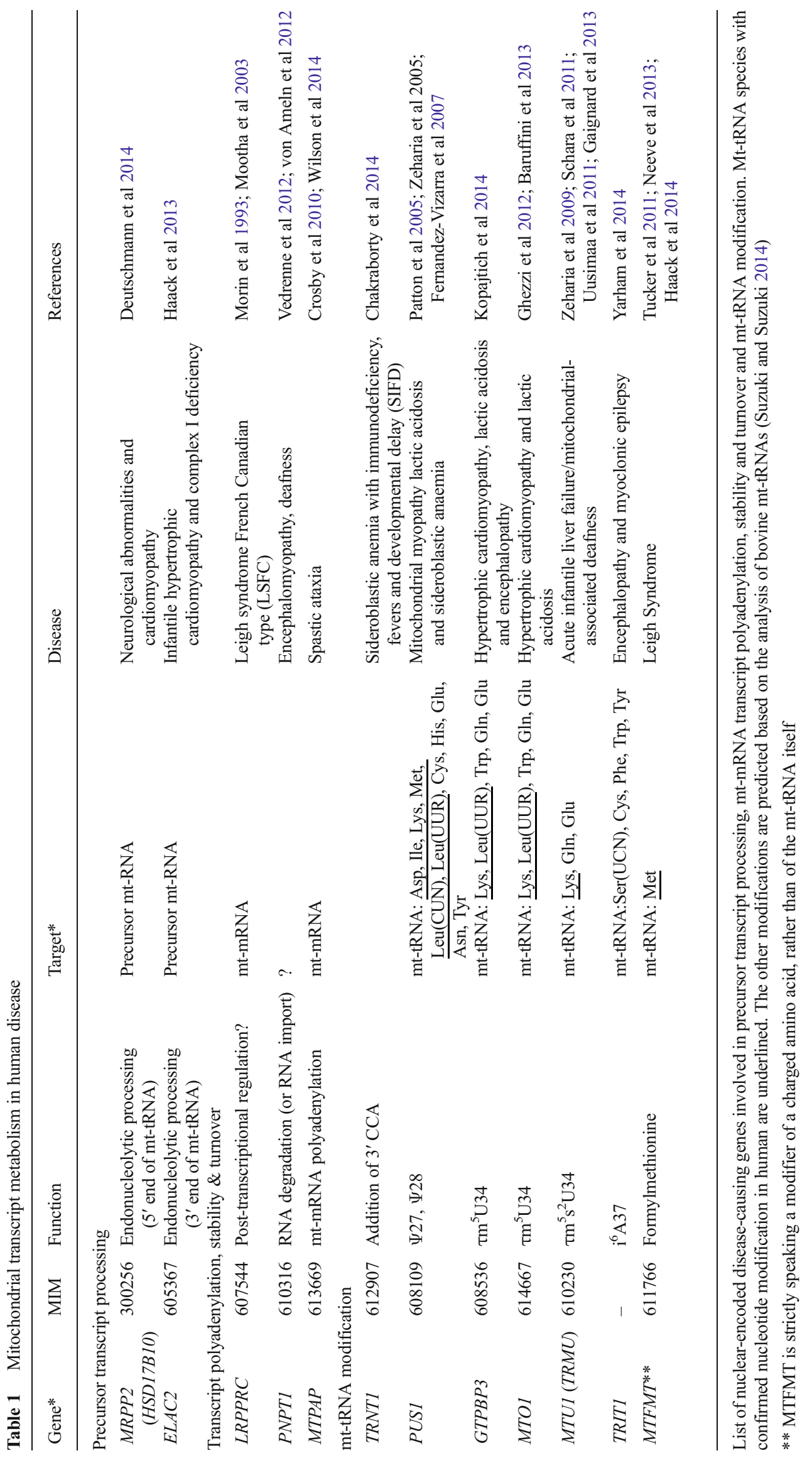


observed, despite the accumulation of unprocessed intermediates.

A further individual, suffering from a mitochondrial disorder, was characterised as having a presumed pathogenic mutation in $E L A C 2$. This patient was identified recently via exome sequencing of 53 patients carrying multiple respiratory chain complex defects (Taylor et al 2014). In the same highthroughput-exome sequencing study a single individual was identified as carrying possible pathogenic mutations in the PTCD1 gene, the protein product of which is thought to directly interact with ELAC2. However, as only a single individual has so far been identified, and mutations in PTCD1 have not previously been associated with a mitochondrial disorder, further investigation will be required to confirm PTCD1 as the causative gene in this case.

\section{Defects of mt-mRNA maturation}

\section{PNPase}

Three studies have identified pathogenic mutations in the PNPT1 gene, encoding PNPase, thought to be involved in mtRNA turnover and possibly RNA import into mitochondria, as earlier described.

The first study, by Vedrenne et al (2012), identified two siblings, born to first-cousin healthy Moroccan parents, suffering with severe but non-progressive encephalopathy accompanied with elevated plasma and cerebrospinal-fluid lactate levels [MIM: 614932]. Affected individuals developed severe hypotonia and movement abnormalities in late infancy. Exome sequencing of the siblings identified a homozygous c. $1160 \mathrm{~A}>\mathrm{G}$ variant in the $P N P T 1$ gene in both individuals. This variant produces a $p$.Gln387Arg transition in the PNPase protein product, with the affected glutamine residue lying within a highly conserved domain of the protein. Mitochondrial translation was shown to be moderately reduced in patient fibroblasts, which is rescued upon reintroduction of wild-type PNPase cDNA, supporting the argument that the variant in PNPT1 is the underlying primary cause of the mitochondrial disorder.

The second study also concerned a single consanguineous Moroccan family, where three siblings were affected by a severe, early onset hearing impairment in early childhood [MIM: 614934] (von Ameln et al 2012). Here, it was shown via genome-wide homozygosity mapping that the three affected siblings carried a homozygous c.1424A $>\mathrm{G}$ mutant variant (p.Glu475Gly) in PNPT1 which co-segregated on the pedigree with the hearing loss.

Recently, an individual in a third suspected family was shown to carry compound heterozygous sequence variants in the PNPT1 gene (Slavotinek et al 2014), a maternally inherited mutation affecting the acceptor splice-site for exon 5, c. $401-1 \mathrm{G}>\mathrm{A}$, and a paternally inherited c.1519G $>\mathrm{T}$ missense mutation (p.Ala507Ser). In this case, as well as clinical presentations, which are consistent with the previous reports (microcephaly, myoclonic epilepsy and sensorineural deafness), the proband also suffers from eye manifestations in the form of left-sided peripheral chorioretinal defect and optic atrophy (Slavotinek et al 2014).

The difference in severity and tissue specificity in the individuals affected across the three studies may reflect a different level of residual PNPase activity for the different mutant variant proteins. This example highlights the heterogeneity of the presentation of mitochondrial disorders.

In the first two reported cases it was shown that the mutations affected homo-trimerisation of PNPase. To determine the exact mechanism perturbed in the disease, both studies focused on the deleterious effect of the mutant PNPase variants on the reported role of PNPase in RNA import, where it was shown that both mutant variants resulted in impaired import of RNAs into mitochondria. However, the exact role of PNPase in human mitochondria is still a subject of debate, and it had not been addressed whether either of the mutant proteins had any effect on the role of PNPase in the mitochondrial matrix, where it has been shown to be involved in mtRNA turnover (Borowski et al 2013).

\section{$m t P A P$}

Six individuals from a large consanguineous Old Order Amish family were reported to carry a homozygous pathogenic mutation in MTPAP. Patients suffer from a slowly progressive autosomal-recessive neurodegenerative disorder characterised by spastic paraparesis, cerebellar ataxia and optic atrophy [MIM: 613669] (Crosby et al 2010). This is also often accompanied with learning difficulties.

Genome wide linkage and homozygosity mapping of affected individuals identified a region of $6.5 \mathrm{Mb}$ at chromosome 10p11.23 as likely to contain the disease locus. Targeted sequencing of genes within this region identified a homozygous c. $1432 \mathrm{~A}>\mathrm{G}$ mutation in MTPAP which cosegregated with the disease phenotype. The mutation results in a predicted p.N478D substitution in a highly conserved region of mtPAP protein.

Mitochondrial poly(A) tail assays using RNA from blood of affected patients revealed a profound reduction of polyadenylation of several mtRNAs in homozygous carriers (Crosby et al 2010), although transcripts did remain oligoadenylated ( $<10 \mathrm{nt} 3^{\prime}$ extension), and a further study was able to confirm that the p.N478D mutant mtPAP retained residual oligoadenylation activity, but not polyadenylation activity (Wilson et al 2014). This highlights polyadenylation of mitochondrial mRNAs as essential for mitochondrial gene expression, as reduction of polyadenylation due to impaired mtPAP activity was later shown to cause a mitochondrial translation defect (Wilson et al 2014). 


\section{$L R P P R C$}

Leigh syndrome French Canadian (LSFC) type [MIM: 220111] is a severe autosomal recessive disorder which presents in the geographically isolated Saguenay-Lac-Saint-Jean region of Quebec, resulting from mutations in the LRPPRC gene. In this region, it is estimated that $\sim 1$ in 23 adults are carriers of the affected mutant LRPPRC allele, resulting in LSFC presenting in around 1 in 2000 births (Morin et al 1993). Genealogical analysis suggests the LRPPRC founder mutation to originate from individuals of the French-Canadian population in Europe in the 17th Century. This founder allele carries a p.A354V mutation at a highly conserved residue of the LRPPRC protein.

LSFC is characterised by severe COX deficiency, which particularly affects the liver and brain, and to a lesser extent in fibroblasts and skeletal muscle, due to a failure to assemble the holoenzyme complex (Merante et al 1993). As with classical Leigh syndrome, affected LSFC patients suffered from a severe neurological disorder characterised by subacute necrotising encephalopathy, but also presented with microvesicular steatosis (Morin et al 1993), likely due to the low levels of COX activity in the liver of patients (Merante et al 1993). Other common presentations include a moderate developmental delay, hypotonia, ataxia, strabismus, opthalmoplegia, optic atrophy and mild facial dysmorphia. Patients suffer from elevated lactate levels in blood and cerebrospinal fluid, and most affected individuals died of fulminant metabolic acidosis, at an average age of between 3 and 5 years (Morin et al 1993).

At a stage when whole exome sequencing was not yet available, the affected genomic locus was narrowed down using genome-wide linkage disequilibrium mapping to a $\sim 2 \mathrm{cM}$ region at 2p16-21 (Lee et al 2001). An integrative genomics approach, where the combination of available genomic DNA data, identification of mRNAs which co-express with known mitochondrial genes and proteomic analysis of mitochondrial proteins, was further used to identify LRPPRC as the affected mitochondrial gene in LSFC (Mootha et al 2003). In this study, 21 out of 22 patients carried homozygous founder mutation alleles, with the remaining patient a compound heterozygote.

In patients fibroblasts, a reduction in level of the mutant LRPPRC protein in mitochondria was associated with a specific reduction in steady state levels of COI and COIII mRNAs, and an accompanied specific reduction in COI and COIII translation products (Xu et al 2004), which could explain the specific COX deficiency in LSFC patients (Merante et al 1993). This would suggest that LRPPRC has a specific mRNA stabilising function for COI and COIII mRNAs.

Recently, it has been proposed that tissue specific differences in the levels of LRPPRC and its interacting partner SLIRP in affected tissues may account for the tissue specific biochemical deficiencies encountered in LSFC. While there is an almost complete lack of complex IV in the liver, there is only a $50 \%$ reduction of COX assembly in the heart (Sasarman et al 2015a).

In unaffected control tissues, fibroblasts exhibited the highest levels of the LRPPRC-SLIRP protein complex, with lower levels in muscle and liver, and almost undetectable levels in control heart tissue (Sasarman et al 2015b). This contrasts with levels of assembled complex IV in these control tissues, where heart carries the highest level of complex IV, and liver and fibroblasts have a reduced level. This may suggest a tissue-specific post-transcriptional handling of mitochondrial mRNAs, where heart tissue may be less dependent on activity of the LRPPRC-SLIRP complex compared to heart and brain, which are the main affected tissues when LRPPRC activity is reduced in LFSC.

Additionally, further depletion of LRPPRC protein levels in patient myoblasts and differentiated myotubes, which suffer from complex I as well as complex IV deficiency, leads to a general OXPHOS complex deficiency in all complexes with subunit contributions from mtDNA (Sasarman et al 2015a). It is possible therefore that while the p.A354V founder mutation protein specifically affects COX transcripts and therefore has a greatest effect on cytochrome oxidase assembly, alternative mutations which confer further loss of residual LRPPRC activity may lead to a more generalised combined OXPHOS deficiency.

\section{Defects of mt-rRNA maturation}

Most enzymes that play a role in mt-rRNA maturation have been discovered only recently and very little is known about their possible pathological role. Mouse models exist for only two of these genes (TFB1M and NSUN4) and for both of them, homozygous gene ablation is embryonic lethal. It has been suggested that the function of TFB1M as $12 \mathrm{~S} \mathrm{mt-rRNA}$ methylase might be related to aminoglycoside antibiotics induced deafness (Raimundo et al 2012). However, recent methylation analysis in patients harbouring mtDNA mutation that predisposes to hearing loss following aminoglycoside antibiotic exposure show no difference in $12 \mathrm{~S}$ mt-rRNA methylation level compared to controls (O'Sullivan et al 2015).

\section{Defects of mitochondrial tRNA maturation}

\section{TRNT1}

The universally conserved CCA sequence is found on the $3^{\prime}$ terminus of all tRNAs. However, it is uncoded in almost all species, with a post-transcriptional polymerisation event required to produce the full length tRNA. Once mature, the newly polymerised $3^{\prime}$ terminus acts as the amino acid attachment site for the tRNAs cognate aminoacyl-tRNA synthetase. 
In human mitochondria, this sequence is created by tRNAnucleotidyltransferase 1 (TRNT1) (Fig. 5) (MIM: 612907). A cohort of patients presenting with SIFD (Sideroblastic anaemia associated with immunodeficiency, periodic fevers and developmental delay) were identified as carrying mutations in TRNT1 (Chakraborty et al 2014). Sideroblastic anaemia, a condition characterised by a reduced ability to incorporate iron into haemoglobin, has been linked to deficiencies in haem synthesis, mitochondrial iron-sulphur cluster biogenesis and mitochondrial translation (Fleming 2011). Some patients were also found to have sensorineural hearing loss, cardiomyopathy and central nervous system abnormalities. All but one of the mutations described were found to have diminished polymerisation activity in an in vitro assay, with the degree of the enzymatic impairment found to correlate with the range of clinical severity found. More recently, two further individuals carrying distinct TRNT1 mutations have been characterised and shown to exhibit an impairment of CCA addition specific to mt-tRNA ${ }^{\text {Ser(AGY) }}$ (Sasarman et al 2015b). Despite this, the two individuals presented with varied clinical features: acute lactic acidosis, severe developmental delay, hypotonia, microcephaly, seizures, progressive cortical atrophy, neurosensorial deafness, sideroblastic anaemia and renal Fanconi syndrome in one case, gait ataxia, dysarthria, gross motor regression, hypotonia, ptosis and ophthalmoplegia in the other.

\section{PUS1}

Given the stabilising role of pseudouridine $(\Psi)$, its absence in mt-tRNAs would be expected to negatively impact translation through the disruption of structure dependent processes, such as its recognition by a cognate aminoacyl-tRNA synthetase, or its accommodation into the $\mathrm{P}$ or $\mathrm{A}$ site of the ribosome. Of the 13 pseudouridine synthases identified in humans, PUS1 is by far the most well characterised, with loss of function mutations in PUS1 resulting in diminished levels of $\Psi 27$ and $\Psi 28$ in human mitochondrial tRNAs (MIM: 609109) (Patton et al 2005) (Fig. 5). Patients with mitochondrial myopathy, lactic acidosis and sideroblastic anaemia (MLASA), along with a concordant decrease in mitochondrial translation rate, have been identified as carrying causative mutations in PUS1 (Bykhovskaya et al 2004a; Fernandez-Vizarra et al 2007). Despite its dual localisation, with substrates including both cytosolic and mitochondrial tRNAs, patients with deleterious mutations in PUS1 have a characteristic mitochondrial phenotype. The relative sparseness of modifications in mitochondrial tRNAs may result in a greater susceptibility compared to their cytosolic counterparts. For example, a stabilising $\Psi 55$ modification that is present in cytosolic tRNAs is frequently absent in mitochondrial tRNAs. Interestingly, Pus1p, the yeast homolog of PUS1 is found to be non-essential for viability, but is lethal in combination with mutations in Pus $4 p$, the tRNA $\Psi 55$ synthase (Grosshans et al 2001).

\section{GTPBP3/MTO1}

The incorporation of taurinomethyl at position 34 to form 5taurinomethyluridine $\left(\tau \mathrm{m}^{5} \mathrm{U}\right)$ has been identified in five mammalian mt-tRNAs: mt-tRNA ${ }^{\mathrm{Leu}(U U R)}$, mt-tRNA ${ }^{\text {Trp }}$, mttRNA $^{\text {Lys }}$, mt-tRNA ${ }^{\text {Gln }}$ and mt-tRNA ${ }^{\text {Glu }}$ (Suzuki and Suzuki 2014). The enzymatic activity responsible for the formation of 5-taurinomethyluridine $\left(\mathrm{\tau m}^{5} \mathrm{U}\right)$ has yet to be definitively demonstrated in humans, however GTPBP3 (MIM: 608536) and MTO1 (MIM: 614667), acting in unison, represent the most likely candidates. Both GTPBP3 and MTO1 have been localised to the mitochondria, and are capable of complementing the mitochondrial phenotypes in yeast strains carrying deletions in their corresponding homologs, MSS1 and MTO1 (Li and Guan 2002; Li et al 2002). Patients presenting with hypertrophic cardiomyopathy, lactic acidosis and a combined OXPHOS deficiency have been found to carry mutations in GTPBP3 (Kopajtich et al 2014) and MTO1 (Ghezzi et al 2012; Baruffini et al 2013). The high degree of similarity of clinical phenotypes between patients with GTPBP3 and MTO1 mutations, an uncharacteristic attribute of mitochondrial disease causing genes, corroborates the notion that these two enzymes act in tandem. The phenotype of an MTO1deficient mouse model is found to accurately reflect that of the above patients (Becker et al 2014), the severity of which is found to be ameliorated by a ketogenic diet (Tischner et al 2015). Additionally, both GTPBP3 and MTO1 have been identified through linkage analysis as modifier genes in nonsyndromic deafness caused by a m.1555A $>$ G mutation in $12 \mathrm{~S}$ mt-rRNA (Bykhovskaya et al 2004b). Despite being present as a homoplasmic population, the $\mathrm{m} .1555 \mathrm{~A}>\mathrm{G}$ mutation results in a broad range of clinical severity from individual to individual, with this variance being modulated by the coinheritance of nuclear-encoded modifier genes (Bykhovskaya et al 1998). Corroboratively, yeast strains bearing a $15 \mathrm{~S}$ rRNA mutation in the corresponding mtDNA position to human $\mathrm{m} .1555 \mathrm{~A}>\mathrm{G}$ are found to result in a respiratory defect only in conjunction with mutations in MSS1 and MTO1, yeast orthologous of human GTPBP3 and MTO1, respectively (Decoster et al 1993; Colby et al 1998).

\section{MTU1 (TRMU)}

Three of the five mt-tRNAs identified as putative GTPBP3/ MTO1 substrates carry a more extensively modified 5taurinomethyl-2-thiouridine $\left(\tau \mathrm{m}^{5} \mathrm{~s}^{2} \mathrm{U}\right)$ wobble base in their mature forms: mt-tRNA ${ }^{\text {Lys }}$, mt-tRNA ${ }^{\text {Gln }}$ and mt-tRNA ${ }^{\text {Glu }}$ (Suzuki et al 2002). As for GTPBP3 and MTO1, yeast deletion strains have greatly assisted in identifying the responsible enzymatic activity, with the loss of the thiouridylase MTU1 (MTO2) resulting in diminished 2-thiolation of mitochondrial tRNAs, with a corresponding impairment of mitochondrial translation. Depletion of the human homolog, MTU1 (MIM: 
610230), also known as TRMU, a mitochondrially localised protein capable of complementing yeast MTU1, also produces a dramatic reduction in tRNA thiolation (Umeda et al 2005). Numerous patients with reversible infantile respiratory chain deficiency, a condition characterised by acute liver failure in infancy, have now been identified as carrying causative mutations in MTU1 (Zeharia et al 2009; Schara et al 2011; Uusimaa et al 2011; Gaignard et al 2013). The hypomodification of substrate tRNAs was not found to result in a significant loss of stability, therefore the resulting defective mitochondrial translation is believed to be due to their impaired decoding capabilities (Zeharia et al 2009). Patients present during early infancy with symptoms of liver dysfunction, however, if they survive the first few months of life, make a full spontaneous recovery. It is postulated that infants may experience a window of vulnerability during neonatal development due to a limited availability of sulphur. MTU1 is predicted to be dependent on the activity of a cysteine desulfurase, NFS1, to transfer sulphur from cysteine (Nakai et al 2004), an amino acid that is described as conditionally essential, at least in early life (Zlotkin and Anderson 1982; Zlotkin and Cherian 1988). Cysteine supplementation during this period has therefore been proposed as a potential treatment (Boczonadi et al 2013). As with GTPBP3 and MTO1 above, MTU1 has also been implicated as a modifier gene in mitochondrial deafness (Yan et al 2006b).

\section{TRIT1}

The existence of the $i^{6} \mathrm{~A} 37$ modification has been demonstrated to improve translation efficiency through the stabilisation of cognate codons, with its loss in yeast, due to deletion of the tit1 gene, resulting in mitochondrial dysfunction and slow growth (Lamichhane et al 2013b). The homologous isopentyltransferase in humans, TRIT1, was initially identified as a tumour suppressor gene (Spinola et al 2005) with certain variants being associated with lung cancer progression. Subsequent siRNA-mediated TRIT1 depletion studies demonstrated diminished $i^{6} \mathrm{~A} 37$ in cytosolic and mitochondrial tRNAs (Lamichhane et al 2013a). Siblings with encephalopathy and myoclonic epilepsy have been identified as carrying causative mutations in TRIT1 with a corresponding loss of the $i^{6} \mathrm{~A}$ modification and compromised mitochondrial translation (Yarham et al 2014).

\section{MTFMT}

As in all translation systems, polypeptide synthesis in mitochondria is initiated with a methionine residue. However, metazoan mitochondria differ in that only a single methionine tRNA is utilised for both initiation and elongation. Segregation instead occurs via a post-transcriptional modification, with the initiator mt-tRNA ${ }^{\text {Met }}$ undergoing an unusual formylation on the methionine residue charged to its $3^{\prime}$ end, thereby increasing its affinity for the mitochondrial initiation factor (IF2 $2_{\mathrm{mt}}$ ) (Spencer and Spremulli 2004). Deficiencies in

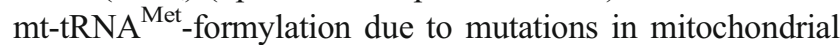
methionyl-tRNA formyltransferase (MTFMT, MIM: 611766) have been identified in a number of patients with Leigh syndrome and combined OXPHOS deficiency (Neeve et al 2013; Haack et al 2014). Significantly reduced mitochondrial translation rates have been identified as the result of pathogenic MTFMT mutations (Tucker et al 2011) and a severely diminished activity of these variants has been demonstrated in vitro (Sinha et al 2014).

\section{Mt-tRNA aminoacyl synthetases}

The key role of mitochondrial aminoacyl-tRNA synthetases (mtARSs) in human pathology affecting mitochondrial translation has been well recognised. However, this large group of disease genes is not covered by this review. Existing recent papers extensively describe the mitochondrial pathologies caused by genetic defects in ARSs (Konovalova and Tyynismaa 2013; Diodato et al 2014; Vanlander et al 2014).

\section{Maturation defects related to primary mtDNA mutations}

Primary mutations in mtDNA can affect almost any step of mtRNA maturation. Below we provide an overview of pathological mtDNA mutations for which involvement in mttRNA, mt-rRNA and mt-mRNA maturation by nuclear encoded genes has been documented.

There are two main types of mtDNA alterations: point mutations, which involve a change of one or a few nucleotides, and large-scale rearrangements, such as large deletions. Unlike the nuclear genome, there are multiple mitochondrial genomes per cell. Therefore, unlike nuclear mutations, which can be either heterozygous or homozygous, mtDNA mutations may be present at any fraction, a condition referred to as heteroplasmy. Cellular physiology is affected only if the mutation fraction in a given cell exceeds a certain threshold, typically >70-90\%, depending on the type of variant and tissues affected. The percentage of mutant mtDNA may vary among individuals and among organs and tissues within the same patient. This, in part, explains the varied clinical phenotype seen in individuals with pathogenic mtDNA mutations (Sciacco et al 1994; Chinnery et al 1997). To complicate this issue even further, one particular base substitution can cause different symptoms in different patients, while a particular syndrome can usually be caused by several possible mutant variants and patients can even evolve from one disease phenotype into another (Schapira 2006). It falls outside the scope of this review to discuss all pathogenic variations. 
A primary mtDNA mutation interfering with mt-mRNA maturation has been described in two reports. An m.9205 $\Delta$ TA microdeletion, on the boundary of two genes, ATP6 and COIII has been reported to underlie cases of seizures and lactic acidosis. Encephalopathy has been observed in only one patient (Seneca et al 1996; Jesina et al 2004). Although the two unrelated patients have identical, nearly homoplasmic mutation levels, biochemical consequences of this microdeletion appear to be very different. One patient had no altered primary transcript processing, but a rapid deadenylation leading to enhanced mt-mRNA decay (Seneca et al 1996; Temperley et al 2003), while the other patient showed affected processing of the primary ATP8/6-COIII transcripts, without polyadenylation impairment (Jesina et al 2004).

Fig. 6 Primary mtDNA mutation affecting mitochondrial RNA maturation. Schematics of the "clover leaf" secondary structure of a generic mitochondrial tRNA indicating the individual positions for which mutations that affect mt-tRNA maturation are described in one or multiple mt-tRNAs (see also Table 2). The "bold circles" show mutations in mt-tRNA ${ }^{\text {Leu(UUR) }}$ that affect mt-rRNA maturation as well as mt-tRNA maturation
Primary mutations interfering with mt-rRNA maturation

Point mutations that interfere with mt-rRNA maturation are actually alterations in mt-tRNA ${ }^{\mathrm{Leu}(\mathrm{UUR})}$, not in mt-rRNA itself (Fig. 6, bold circles). The common m.A3243A $>$ G MELAS (mitochondrial encephalomyopathy, lactic acidosis and stroke-like episodes) mutation (King et al 1992), as well as m.3271 T $>$ C, m.3303C $>$ T (Koga et al 2003), m.3302A $>$ G (Bindoff et al 1993), m.3260 $\mathrm{A}>\mathrm{G}$ and m.3256C $>\mathrm{T}$ (Rossmanith and Karwan 1998), all interfere with end processing of mt-tRNA ${ }^{\text {Leu(UUR) }}$. This causes an accumulation of a precursor RNA consisting of $16 \mathrm{~S}$ mt-rRNA linked to mt-tRNA ${ }^{\text {Leu(UUR) }}$ and ND1 (also known as RNA19) (Rossmanith and Karwan 1998). Although these mutations seem to interfere with $16 \mathrm{~S}$ mt-rRNA maturation it is presumably not the crucial disease-causing molecular pathway in patients (see below, Table 2).

metRA maturation

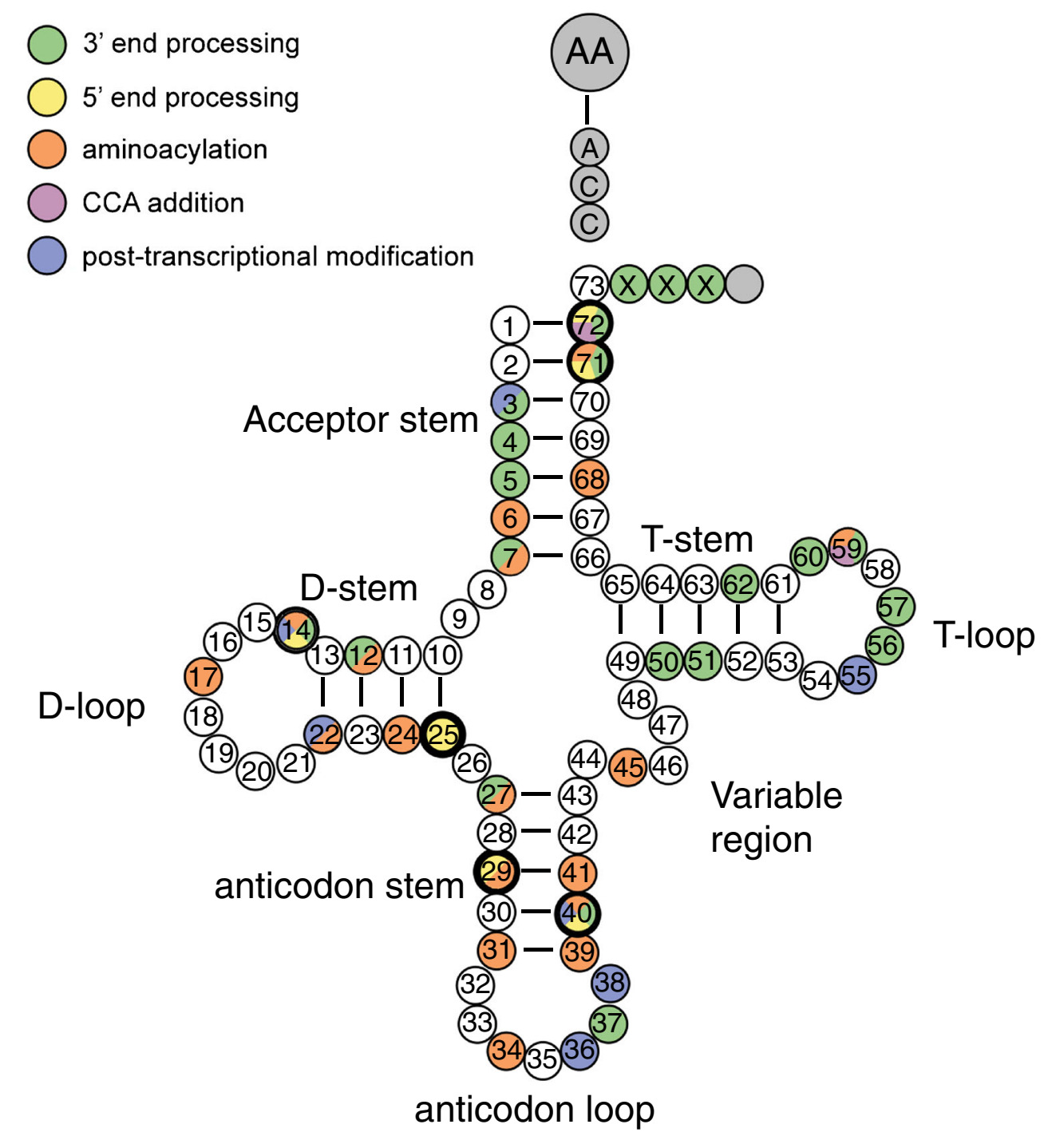

mutation in mt-tRNA ${ }^{\text {Leu(UUR) }}$ that affects mt-rRNA maturation 


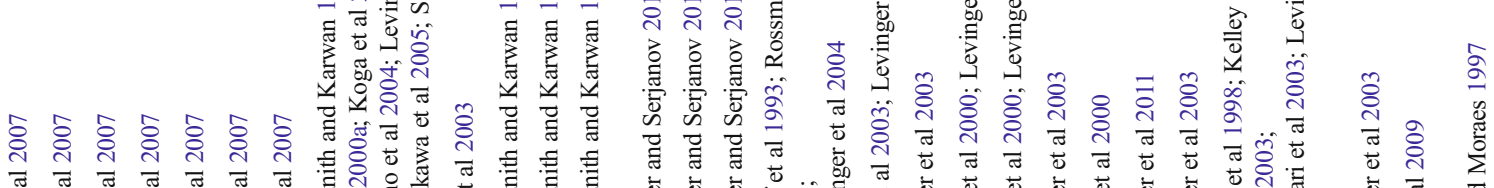

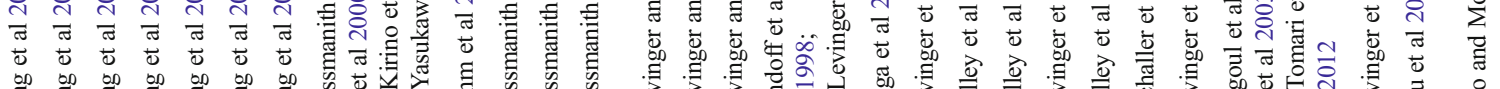

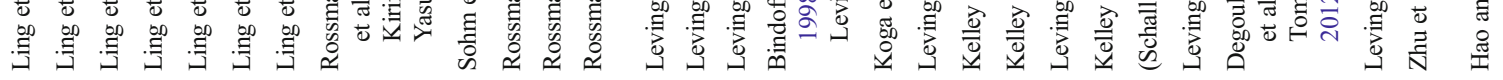

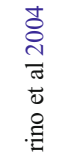

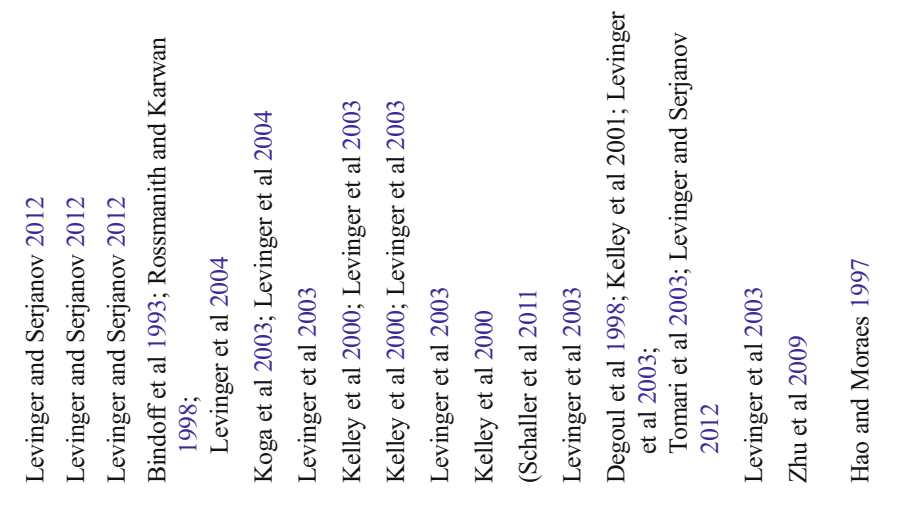

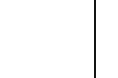

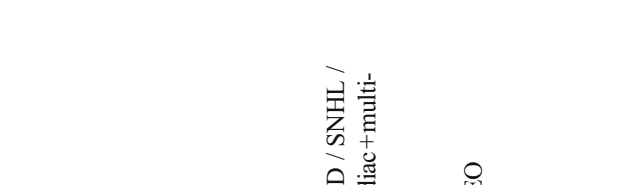<smiles>[CH]C</smiles>
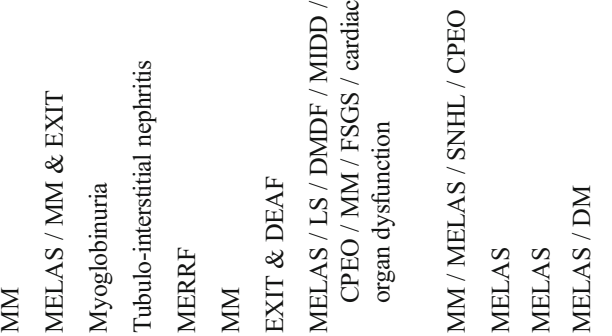<smiles>CC(C)C1CCCCC1</smiles><smiles>CCCCC</smiles>

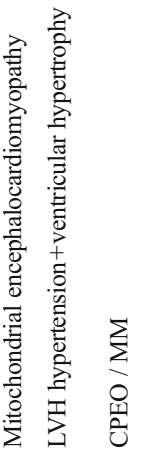
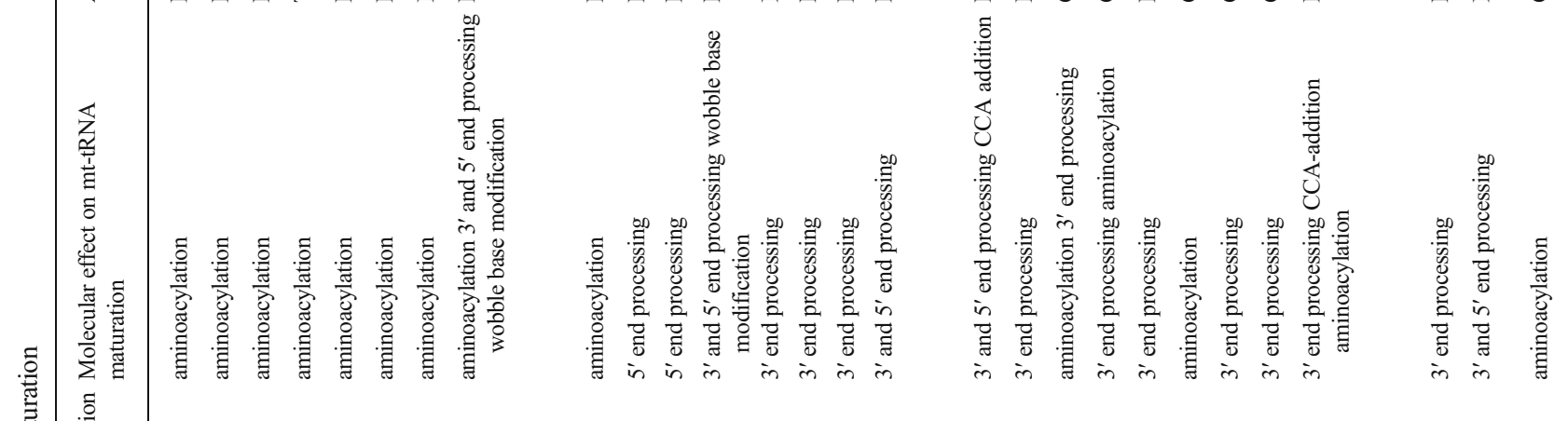
ชก ปล⿻่ 소ำ กิ 


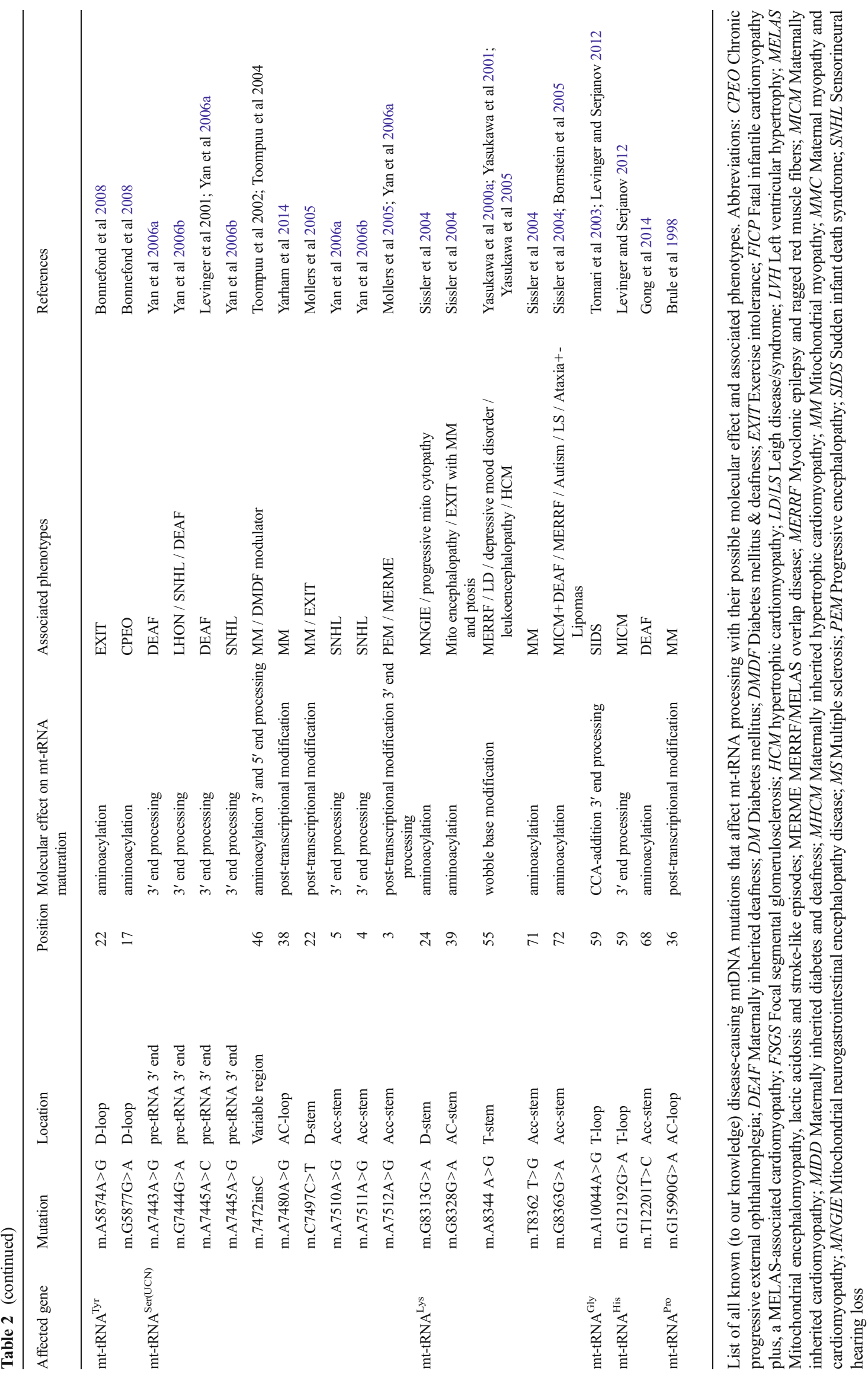




\section{Primary mutations causing mt-tRNA maturation defects}

While mt-tRNA genes only count for approximately $5 \%$ of the total mtDNA sequence, they have been linked with the majority of mitochondrial DNA diseases (Anderson et al 1981; Yarham et al 2010). Different base substitutions in the same mt-tRNA or even the same point mutation can lead to different clinical features. The molecular mechanisms are often poorly understood. Some mutations disrupt transcription factor binding, while others lead to codon recognition problems. The same base substitution can have an effect on more than one maturation step. This has been shown for the MERR F (myoclonic epilepsy with ragged red fibers) m.8344A $>\mathrm{G}$ and MELAS m.3243A $>$ G mutation amongst others. We will discuss the molecular mechanism by which these two mutations contribute to pathogenesis only briefly; more details can be found in a review by Yarham et al (2010).

\section{Primary mutations interfering with mt-tRNA end} processing Following polycistronic transcription, endonucleolytic 5'- and 3'-end cleavage of precursor mt-tRNA molecules and subsequent 3 '-CCA addition are essential to produce mature mt-tRNAs. Several point mutations interfere with one or more of these steps (Table 2, Fig. 6, green, yellow and violet).

Only a few studies have analysed the effect of mt-tRNA mutations on $5^{\prime}$ end leader sequence processing. Ten mutations in the mt-tRNA ${ }^{\text {Leu(UUR) }}$ gene were analysed. Four of them, all associated with MELAS, showed a great decrease in RNase P processing, especially $\mathrm{m} .3256 \mathrm{C}>\mathrm{T}$ (Moraes et al 1993). This leads to a precursor RNA consisting of $16 \mathrm{~S}$ mtrRNA linked to mt-tRNA ${ }^{\text {Leu(UUR) }}$ and ND1 as explained above (Rossmanith and Karwan 1998). It also has been shown that m.7472insC impairs $5^{\prime}$ end processing of $\mathrm{mt}$ tRNA $^{\text {Ser(UCN) }}$. Interestingly, this insertion also causes $3^{\prime}$ end processing impairment and it was shown that misprocessing at the $3^{\prime}$ end promotes misprocessing at the $5^{\prime}$ end.

Alterations near the mt-tRNA 3' end could have a deleterious effect on $3^{\prime}$ end endonucleolytic processing. This is indeed observed for tRNA ${ }^{\text {Leu(UUR) }}$ mutations m.3303C $>$ T and m.3302A $>\mathrm{G}$ as both show a strong interference with $3^{\prime}$ end cleavage (Levinger et al 2004). Interestingly, also non-coding mutations in the pre-tRNA $3^{\prime}$ end of mt-tRNA ${ }^{\text {Ser(UCN) }}$ strongly affect the efficiency of $3^{\prime}$ end processing. Four base substitutions were investigated and displayed different effects. m.7443A $>\mathrm{G}$ and $\mathrm{m} .7445 \mathrm{~A}>\mathrm{C}$ gave a strong decrease in ELAC2 efficiency, while another mutation of the same nucleotide $(\mathrm{m} .7445 \mathrm{~A}>\mathrm{G})$ has a lower decrease, although cleavage predominantly shifts one nucleotide towards the $3^{\prime}$ end from the normal cleavage site. $\mathrm{m} .7444 \mathrm{G}>\mathrm{A}$ shows an increased efficiency, but this cleavage has also shifted by one nucleotide in the $3^{\prime}$ direction of the normal cleavage site (Yan et al 2006a).
Pathogenic substitutions in the mt-tRNA T-arm may also cause impaired $3^{\prime}$ end cleavage, as the T-arm plays an important role in ELAC2 recognition (Hopkinson and Levinger 2008). All mt-tRNAs with a pathogenic mutation in the Tarm studied by Levinger and Serjanov (2012), showed a reduced ELAC2 processing efficiency. The strongest decrease was observed in the mt-tRNA ${ }^{\text {Ile }} \mathrm{m} .4317 \mathrm{~A}>\mathrm{G}$ mutation. This effect on $3^{\prime}$ end cleavage is presumably due to a structural change in the T-arm that impairs precursor binding to ELAC2 (Levinger and Serjanov 2012). Another study analysed the effect of pathogenic mutations in mt-tRNA ${ }^{\text {Ile }}$ on $3^{\prime}$ end cleavage. Ten base substitutions were investigated and they all showed a reduced ELAC2 processing, confirming the importance of the T-arm in 3' end cleavage. However, the mt-tRNA ${ }^{\text {Ile }}$ m.4269A $>$ G mutation, located in the acceptor stem, caused the greatest decrease in $3^{\prime}$ processing efficiency. Other substitutions in the acceptor stem such as $\mathrm{m} .7512 \mathrm{~A}>\mathrm{G}$, m.7511 $\mathrm{A}>\mathrm{G}$ and m.7510A $>\mathrm{G}$ in mt-tRNA ${ }^{\mathrm{Ser}(\mathrm{UCN})}$ also produce a mild decrease in ELAC2 processing (Yan et al 2006b).

CCA addition on the $3^{\prime}$ end of mt-tRNAs is another essential step for mt-tRNA maturation. Only few substitutions are known to impair CCA addition by TRNT1, such as m.4317A $>\mathrm{G}$ in mt-tRNA ${ }^{\text {Ile }}$ (Tomari et al 2003). However, as mentioned above, this mutation also severely impairs $3^{\prime}$ end cleavage (Levinger and Serjanov 2012). It is speculated that the effect on CCA addition is the result of inappropriate positioning of the tRNA substrate on the enzyme, possibly owing to the structural change in the T-arm. Another mutation that affects CCA addition, m.3303C $>$ T in mt-tRNA ${ }^{\text {Leu(UUR), }}$ is located in the acceptor stem and presumably decreases the affinity of the enzyme (Levinger et al 2004).

\section{Primary mutations interfering with mt-tRNA} aminoacylation Only mature and correctly folded mttRNAs can be aminoacylated. Therefore, many mt-tRNA mutations impair aminoacylation efficiency or lead to mischarging (Fig. 6, red). Mutations that frequently affect mt-tRNA aminoacylation are located in the acceptor stem, such as mt-tRNA ${ }^{\text {Lys }} \mathrm{m} .8362 \mathrm{~T}>\mathrm{G}$ and $\mathrm{m} .8363 \mathrm{G}>\mathrm{A}$ (Sissler et al 2004). D-loop mutations that lead to reduced aminoacylation have also been reported. For example, mttRNA $^{\text {Tyr }}$ m.5874A $>\mathrm{G}$ and $\mathrm{m} .5877 \mathrm{G}>\mathrm{A}$ (Bonnefond et al 2008) impair tyrosylation by perturbing the tertiary folding and destabilising the D-loop. Interestingly, two different substitutions of the same nucleotide (position 14) of mttRNA $^{\text {Leu(UUR) }}, m .3243 \mathrm{~A}>\mathrm{G}$ and m.3243A $>$ T lead to markedly different losses in leucylation efficiency (10-fold and 300 -fold, respectively), possibly due to their function in recognition by its cognate tRNA-aminoacyl synthetase (Asahara et al 1998; Sohm et al 2003). The m.3243A > G MELAS mutation also leads to mischarging and consequently to amino acid misincorporation during mitochondrial translation (Sasarman et al 2008). Mischarging is also suggested to 
contribute to pathogenesis of another MELAS mutation (m.3271 T>C) (Hayashi et al 1993; Sasarman et al 2008).

As discussed above, mutations in the T-arm are generally more prone to impair $3^{\prime}$ end cleavage, while mutations in the D-loop tend to affect aminoacylation. It is speculated that there might be a reciprocal relationship, at least for tRNA ${ }^{\text {Leu(UUR) }}$. Mutations that strongly reduce $3^{\prime}$ end processing seem to have little or no effect on aminoacylation after cleavage, while those with reduced aminoacylation capacity affect $3^{\prime}$ processing the least (Levinger et al 2003). Despite this, it is difficult to predict the pathological mechanism based on the position of the substituted nucleotide. For example, two mutations at nucleotide position 72 of mt-tRNA ${ }^{\text {Leu(UUR) }}$ $(\mathrm{m} .3303 \mathrm{C}>\mathrm{T})$ and $\mathrm{mt}-\mathrm{tRNA}{ }^{\text {Lys }}(\mathrm{m} .8363 \mathrm{G}>\mathrm{A})$ have opposite effects (Tuppen et al 2012), with the different mutations either causing impaired $3^{\prime}$ end processing and CCA addition, but with unaffected aminoacylation (Levinger et al 2003; Sohm et al 2003) or a diminished aminoacylation capacity (Bornstein et al 2005), respectively.

Although many mutations have been reported to affect aminoacylation, it is usually unknown whether this is the primary effect of the mutation or the consequence of a structural change in the mt-tRNA caused by the nucleotide substitution. This was shown for mutations in the mt-tRNA ${ }^{\text {Phe }}$ gene. All studied pathogenic mutations had an effect on aminoacylation, but only in one of them, m.611G $>\mathrm{A}$, an atypical MERRF mutation (Mancuso et al 2004), this seems to be the primary effect (Ling et al 2007).

\section{Primary mutations interfering with mt-tRNA} modifications An important step in the post-transcriptional maturation of mt-tRNA is modification of specific nucleotides (see above, Fig. 6, blue). The following mutations have been associated with a loss of taurinomethyl modification at the wobble base (position 34): two in mt-tRNA ${ }^{\mathrm{Leu}(\mathrm{UUR})}, \mathrm{m} .3243 \mathrm{~A}>\mathrm{G}$ and m.3271 $\mathrm{T}>\mathrm{C}$ (Yasukawa et al 2000a) and one in mttRNA ${ }^{\text {Lys }}$, m.8344A $>$ G (Yasukawa et al 2000b). Wild-type mttRNA ${ }^{\text {Leu(UUR) }}$ recognises UUG and UUA, while mt-tRNA ${ }^{\text {Lys }}$ translates UUU and UUC. Interestingly, the two mttRNA ${ }^{\text {Leu(UUR) }}$ mutations were shown to have a severe reduced UUG translation, while UUA recognition was apparently unaffected (Kirino et al 2004), whereas mt-tRNA ${ }^{\text {Lys }}$ m.8344A $>\mathrm{G}$ leads to a complete loss of codon-anticodon pairing for both UUU and UUC (Yasukawa et al 2001). There are two reported mutations at mt-tRNA position $36, \mathrm{~m} .15990 \mathrm{G}>\mathrm{A}$ in $\mathrm{mt}-$ tRNA $^{\text {Pro }}$ and m.7480A $>$ G in mt-tRNA ${ }^{\text {Ser(UCN) }}$, both linked with mitochondrial myopathy, that directly affect modification of the neighbouring nucleotide (position 37) (Brule et al 1998; Yarham et al 2014). Enzymes involved in mt-tRNA maturation, such as MTO1, GTPBP3, MTU1 or TRIT1, must have a broad specificity, so their function might be structure-dependent rather than sequence-dependent. In a wider context, this could explain why several mutations have an effect on multiple levels, since several pathogenic base substitutions introduce structural changes.

\section{Concluding note}

Recent research has revealed the important role of mtRNA posttranscriptional maturation in human mitochondrial disease, with mutations in several nDNA- and mtDNA-encoded genes being identified as the genetic cause for these disorders (Tables 1 and 2). Nonetheless, the mechanistic details for the genesis of pathologies associated with defects in mtRNA metabolism remain poorly understood. It is now time to strengthen our efforts to elucidate the molecular machinery and mechanisms responsible for regulating post-transcriptional stages of mtRNA biology. Special attention should be given to functionally assign novel genes involved in mtRNA metabolism. This point is particularly important for a further development of mitochondrial medicine as, despite recent advances in next-generation sequencing technologies, defining the genetic cause of the many unsolved cases of mitochondrial disease remains a major challenge. This research will help to understand the remarkable heterogeneity of human pathologies associated with defects of mtRNA metabolism (Table 1) and to stimulate further studies aimed at the development of effective treatments for these otherwise untreatable diseases.

Acknowledgments We are grateful to other members of the Mitochondrial Genetics group at the MRC Mitochondrial Biology Unit for their help during the work on the manuscript. This work was funded by the Medical Research Council (MRC), and EMBO (ALFT 701-2013 to L.V.H).

Compliance with ethics guidelines This article does not contain any studies with human or animal subjects performed by the any of the authors.

All authors contributed to the writing and editing of the manuscript.

\section{Conflict of interest None.}

Open Access This article is distributed under the terms of the Creative Commons Attribution 4.0 International License (http:// creativecommons.org/licenses/by/4.0/), which permits unrestricted use, distribution, and reproduction in any medium, provided you give appropriate credit to the original author(s) and the source, provide a link to the Creative Commons license, and indicate if changes were made.

\section{References}

Agaronyan K, Morozov YI, Anikin M, Temiakov D (2015) Mitochondrial biology. Replication-transcription switch in human mitochondria. Science 347:548-551

Amunts A, Brown A, Toots J, Scheres SH, Ramakrishnan V (2015) Ribosome. The structure of the human mitochondrial ribosome. Science 348:95-98

Anderson S, Bankier AT, Barrell BG et al (1981) Sequence and organization of the human mitochondrial genome. Nature 290:457-465

Antonicka H, Shoubridge EA (2015) Mitochondrial RNA granules are centers for posttranscriptional RNA processing and ribosome biogenesis. Cell Reports 10:920-932 
Antonicka H, Sasarman F, Nishimura T, Paupe V, Shoubridge EA (2013) The mitochondrial RNA-binding protein GRSF1 localizes to RNA granules and is required for posttranscriptional mitochondrial gene expression. Cell Metab 17:386-398

Asahara H, Nameki N, Hasegawa T (1998) In vitro selection of RNAs aminoacylated by Escherichia coli leucyl-tRNA synthetase. J Mol Biol 283:605-618

Baer RJ, Dubin DT (1981) Methylated regions of hamster mitochondrial ribosomal RNA: structural and functional correlates. Nucl Acids Res 9:323-337

Bai Y, Srivastava SK, Chang JH, Manley JL, Tong L (2011) Structural basis for dimerization and activity of human PAPD1, a noncanonical poly(A) polymerase. Mol Cell 41:311-320

Bare LA, Uhlenbeck OC (1986) Specific substitution into the anticodon loop of yeast tyrosine transfer RNA. Biochemistry 25:5825-5830

Baruffini E, Dallabona C, Invernizzi F et al (2013) MTO1 mutations are associated with hypertrophic cardiomyopathy and lactic acidosis and cause respiratory chain deficiency in humans and yeast. Hum Mutat 34:1501-1509

Baughman JM, Nilsson R, Gohil VM, Arlow DH, Gauhar Z, Mootha VK (2009) A computational screen for regulators of oxidative phosphorylation implicates SLIRP in mitochondrial RNA homeostasis. PLoS Genet 5, e1000590

Becker L, Kling E, Schiller E et al (2014) MTO1-deficient mouse model mirrors the human phenotype showing complex I defect and cardiomyopathy. PLoS One 9, e114918

Bilbille Y, Gustilo EM, Harris KA et al (2011) The human mitochondrial tRNAMet: structure/function relationship of a unique modification in the decoding of unconventional codons. J Mol Biol 406:257-274

Bindoff LA, Howell N, Poulton J et al (1993) Abnormal RNA processing associated with a novel tRNA mutation in mitochondrial DNA. A potential disease mechanism. J Biol Chem 268:19559-19564

Boczonadi V, Horvath R (2014) Mitochondria: impaired mitochondrial translation in human disease. Int J Biochem Cell Biol 48:77-84

Boczonadi V, Smith PM, Pyle A et al (2013) Altered 2-thiouridylation impairs mitochondrial translation in reversible infantile respiratory chain deficiency. Hum Mol Genet 22:4602-4615

Bonnefond L, Florentz C, Giege R, Rudinger-Thirion J (2008) Decreased aminoacylation in pathology-related mutants of mitochondrial tRNATyr is associated with structural perturbations in tRNA architecture. RNA 14:641-648

Bornstein B, Mas JA, Patrono C et al (2005) Comparative analysis of the pathogenic mechanisms associated with the G8363A and A8296G mutations in the mitochondrial tRNA(Lys) gene. Biochem J 387: 773-778

Borowski LS, Dziembowski A, Hejnowicz MS, Stepien PP, Szczesny RJ (2013) Human mitochondrial RNA decay mediated by PNPasehSuv3 complex takes place in distinct foci. Nucl Acids Res 41: $1223-1240$

Brown A, Amunts A, Bai XC et al (2014) Structure of the large ribosomal subunit from human mitochondria. Science 346:718-722

Brule H, Holmes WM, Keith G, Giege R, Florentz C (1998) Effect of a mutation in the anticodon of human mitochondrial tRNAPro on its post-transcriptional modification pattern. Nucl Acids Res 26:537543

Brule H, Elliott M, Redlak M, Zehner ZE, Holmes WM (2004) Isolation and characterization of the human tRNA-(N1G37) methyltransferase (TRM5) and comparison to the Escherichia coli TrmD protein. Biochemistry 43:9243-9255

Bruni F, Gramegna P, Oliveira JM, Lightowlers RN, ChrzanowskaLightowlers ZM (2013) REXO2 is an oligoribonuclease active in human mitochondria. PLoS One 8, e64670

Brzezniak LK, Bijata M, Szczesny RJ, Stepien PP (2011) Involvement of human ELAC2 gene product in $3^{\prime}$ end processing of mitochondrial tRNAs. RNA Biol 8:616-626
Bykhovskaya Y, Shohat M, Ehrenman K et al (1998) Evidence for complex nuclear inheritance in a pedigree with nonsyndromic deafness due to a homoplasmic mitochondrial mutation. Am J Med Genet 77: 421-426

Bykhovskaya Y, Casas K, Mengesha E, Inbal A, Fischel-Ghodsian N (2004a) Missense mutation in pseudouridine synthase 1 (PUS1) causes mitochondrial myopathy and sideroblastic anemia (MLASA). Am J Hum Genet 74:1303-1308

Bykhovskaya Y, Mengesha E, Wang D et al (2004b) Human mitochondrial transcription factor B1 as a modifier gene for hearing loss associated with the mitochondrial A1555G mutation. Mol Genet Metab 82:27-32

Cabello-Villegas J, Winkler ME, Nikonowicz EP (2002) Solution conformations of unmodified and $\mathrm{A}(37) \mathrm{N}(6)$-dimethylallyl modified anticodon stem-loops of Escherichia coli tRNA(Phe). J Mol Biol 319:1015-1034

Camara Y, Asin-Cayuela J, Park CB et al (2011) MTERF4 regulates translation by targeting the methyltransferase NSUN4 to the mammalian mitochondrial ribosome. Cell Metab 13:527-539

Chakraborty PK, Schmitz-Abe K, Kennedy EK et al (2014) Mutations in TRNT1 cause congenital sideroblastic anemia with immunodeficiency, fevers, and developmental delay (SIFD). Blood 124:28672871

Chang DD, Clayton DA (1984) Precise identification of individual promoters for transcription of each strand of human mitochondrial DNA. Cell 36:635-643

Chen JX, Yan SD (2007) Amyloid-beta-induced mitochondrial dysfunction. J Alzheimers Dis 12:177-184

Chen H-W, Rainey RN, Balatoni CE et al (2006) Mammalian polynucleotide phosphorylase is an intermembrane space RNase that maintains mitochondrial homeostasis. Mol Cell Biol 26:8475-8487

Chinnery PF, Howell N, Lightowlers RN, Turnbull DM (1997) Molecular pathology of MELAS and MERRF. The relationship between mutation load and clinical phenotypes. Brain 120(Pt 10):1713-1721

Christianson TW, Clayton DA (1988) A tridecamer DNA sequence supports human mitochondrial RNA 3 '-end formation in vitro. Mol Cell Biol 8:4502-4509

Chujo T, Suzuki T (2012) Trmt61B is a methyltransferase responsible for 1-methyladenosine at position 58 of human mitochondrial tRNAs. RNA (New York, NY) 18:2269-2276

Chujo T, Ohira T, Sakaguchi Y et al (2012) LRPPRC/SLIRP suppresses PNPase-mediated mRNA decay and promotes polyadenylation in human mitochondria. Nucl Acids Res 40:8033-8047

Colby G, Wu M, Tzagoloff A (1998) MTO1 codes for a mitochondrial protein required for respiration in paromomycin-resistant mutants of Saccharomyces cerevisiae. J Biol Chem 273:27945-27952

Cotney J, Shadel GS (2006) Evidence for an early gene duplication event in the evolution of the mitochondrial transcription factor B family and maintenance of rRNA methyltransferase activity in human mtTFB1 and mtTFB2. J Mol Evol 63:707-717

Crosby AH, Patel H, Chioza BA et al (2010) Defective mitochondrial mRNA maturation is associated with spastic ataxia. Am J Hum Genet 87:655-660

Dairaghi DJ, Shadel GS, Clayton DA (1995) Addition of a 29 residue carboxyl-terminal tail converts a simple HMG box-containing protein into a transcriptional activator. J Mol Biol 249:11-28

Dalla Rosa I, Durigon R, Pearce SF et al (2014) MPV17L2 is required for ribosome assembly in mitochondria. Nucl Acids Res 42:8500-8515

Dalluge J (1996) Conformational flexibility in RNA: the role of dihydrouridine. Nucl Acids Res 24:1073-1079

Davis DR (1995) Stabilization of RNA stacking by pseudouridine. Nucl Acids Res 23:5020-5026

Decatur WA, Fournier MJ (2002) rRNA modifications and ribosome function. Trends Biochem Sci 27:344-351 
Decoster E, Vassal A, Faye G (1993) MSS1, a nuclear-encoded mitochondrial GTPase involved in the expression of COX1 subunit of cytochrome c oxidase. J Mol Biol 232:79-88

Degoul F, Brule H, Cepanec C, et al (1998) Isoleucylation properties of native human mitochondrial tRNAIle and tRNAIle transcripts. Implications for cardiomyopathy-related point mutations (4269, 4317) in thetRNAIle gene. Hum Mol Genet 7:347-354

Deutschmann AJ, Amberger A, Zavadil C et al (2014) Mutation or knock-down of 17beta-hydroxysteroid dehydrogenase type 10 cause loss of MRPP1 and impaired processing of mitochondrial heavy strand transcripts. Hum Mol Genet 23:3618-3628

Diffley JF, Stillman B (1991) A close relative of the nuclear, chromosomal high-mobility group protein HMG1 in yeast mitochondria. Proc Natl Acad Sci U S A 88:7864-7868

Diodato D, Ghezzi D, Tiranti V (2014) The mitochondrial aminoacyl tRNA synthetases: genes and syndromes. Int J Cell Biol 2014: 787956

Dubin DT, Taylor RH (1978) Modification of mitochondrial ribosomal RNA from hamster cells: the presence of $\mathrm{GmG}$ and late-methylated UmGmU in the large subunit (17S) RNA. J Mol Biol 121:523-540

Falkenberg M, Gaspari M, Rantanen A, Trifunovic A, Larsson NG, Gustafsson CM (2002) Mitochondrial transcription factors B1 and B2 activate transcription of human mtDNA. Nat Genet 31:289-294

Fernandez-Silva P, Martinez-Azorin F, Micol V, Attardi G (1997) The human mitochondrial transcription termination factor (mTERF) is a multizipper protein but binds to DNA as a monomer, with evidence pointing to intramolecular leucine zipper interactions. EMBO J 16:1066-1079

Fernandez-Vizarra E, Berardinelli A, Valente L, Tiranti V, Zeviani M (2007) Nonsense mutation in pseudouridylate synthase 1 (PUS1) in two brothers affected by myopathy, lactic acidosis and sideroblastic anaemia (MLASA). J Med Genet 44:173-180

Fleming MD (2011) Congenital sideroblastic anemias: iron and heme lost in mitochondrial translation. Hematology Am Soc Hematol Educ Program 2011:525-531

Gaignard P, Gonzales E, Ackermann O et al (2013) Mitochondrial infantile liver disease due to TRMU gene mutations: three new cases. JIMD reports 11:117-123

Garstka HL, Schmitt WE, Schultz J et al (2003) Import of mitochondrial transcription factor A (TFAM) into rat liver mitochondria stimulates transcription of mitochondrial DNA. Nucl Acids Res 31:5039-5047

Ghezzi D, Baruffini E, Haack TB et al (2012) Mutations of the mitochondrial-tRNA modifier MTO1 cause hypertrophic cardiomyopathy and lactic acidosis. Am J Hum Genet 90:1079-1087

Gohil VM, Nilsson R, Ca B-T, Luo B, Root DE, Mootha VK (2010) Mitochondrial and nuclear genomic responses to loss of LRPPRC expression. J Biol Chem 285:13742-13747

Gong S, Peng Y, Jiang P, et al (2014) A deafness-associated tRNAHis mutation alters the mitochondrial function, ROS production and membrane potential. Nucleid Acids Research 42:8039-8048

Greber BJ, Boehringer D, Leitner A et al (2014) Architecture of the large subunit of the mammalian mitochondrial ribosome. Nature 505: 515-519

Grosshans H, Lecointe F, Grosjean H, Hurt E, Simos G (2001) Pus1pdependent tRNA pseudouridinylation becomes essential when tRNA biogenesis is compromised in yeast. J Biol Chem 276: 46333-46339

Haack TB, Kopajtich R, Freisinger P et al (2013) ELAC2 mutations cause a mitochondrial RNA processing defect associated with hypertrophic cardiomyopathy. Am J Hum Genet 93:211-223

Haack TB, Gorza M, Danhauser K et al (2014) Phenotypic spectrum of eleven patients and five novel MTFMT mutations identified by exome sequencing and candidate gene screening. Mol Genet Metab 111:342-352

Hao H, Moraes CT (1997) A disease-associated G5703A mutation in human mitochondrial DNA causes a conformational change and a marked decrease in steady-state levels of mitochondrial tRNA(Asn). Mol Cell Biol 17:6831-6837

Harmel J, Ruzzenente B, Terzioglu M, Spåhr H, Falkenberg M, Larsson NG (2013) The leucine-rich pentatricopeptide repeat-containing protein (LRPPRC) does not activate transcription in mammalian mitochondria. J Biol Chem 288:15510-15519

Harrington KM, Nazarenko IA, Dix DB, Thompson RC, Uhlenbeck OC (1993) In vitro analysis of translational rate and accuracy with an unmodified tRNA. Biochemistry 32:7617-7622

Hayashi J, Ohta S, Takai D et al (1993) Accumulation of mtDNA with a mutation at position 3271 in tRNA(Leu)(UUR) gene introduced from a MELAS patient to HeLa cells lacking mtDNA results in progressive inhibition of mitochondrial respiratory function. Biochem Biophys Res Commun 197:1049-1055

Helm M, Brule H, Degoul F et al (1998) The presence of modified nucleotides is required for cloverleaf folding of a human mitochondrial tRNA. Nucl Acids Res 26:1636-1643

Helm M, Giegé R, Florentz C (1999) A Watson-Crick base-pairdisrupting methyl group (m 1 A9) is sufficient for cloverleaf folding of human mitochondrial tRNA Lys. Biochemistry 38:13338-13346

Holzmann J, Frank P, Loffler E, Bennett KL, Gerner C, Rossmanith W (2008) RNase P without RNA: identification and functional reconstitution of the human mitochondrial tRNA processing enzyme. Cell 135:462-474

Hopkinson A, Levinger L (2008) Effects of conserved D/T loop substitutions in the pre-tRNA substrate on tRNase Z catalysis. RNA Biol 5:104-111

Jesina P, Tesarova M, Fornuskova D et al (2004) Diminished synthesis of subunit a (ATP6) and altered function of ATP synthase and cytochrome c oxidase due to the mtDNA $2 \mathrm{bp}$ microdeletion of TA at positions 9205 and 9206. Biochem J 383:561-571

Johansson MJO, Esberg A, Huang B, Björk GR, Byström AS (2008) Eukaryotic wobble uridine modifications promote a functionally redundant decoding system. Mol Cell Biol 28:3301-3312

Jourdain AA, Koppen M, Wydro M et al (2013) GRSF1 regulates RNA processing in mitochondrial RNA granules. Cell Metab 17:399-410

Jourdain AA, Koppen M, Rodley CD et al (2015) A mitochondriaspecific isoform of FASTK is present in mitochondrial RNA granules and regulates gene expression and function. Cell Reports 10: $1110-1121$

Kaushal PS, Sharma MR, Booth TM et al (2014) Cryo-EM structure of the small subunit of the mammalian mitochondrial ribosome. Proc Natl Acad Sci U S A 111:7284-7289

Kazak L, Reyes A, Duncan AL et al (2013) Alternative translation initiation augments the human mitochondrial proteome. Nucl Acids Res 41:2354-2369

Kelley SO, Steinberg SV, Schimmel P et al (2000) Functional defects of pathogenic human mitochondrial tRNAs related to structural fragility. Nat Struct Biol 7:862-865

Khidr L, Wu G, Davila A, Procaccio V, Wallace D, Lee W-H (2008) Role of SUV3 helicase in maintaining mitochondrial homeostasis in human cells. J Biol Chem 283:27064-27073

King MP, Koga Y, Davidson M, Schon EA (1992) Defects in mitochondrial protein synthesis and respiratory chain activity segregate with the tRNA(Leu(UUR)) mutation associated with mitochondrial myopathy, encephalopathy, lactic acidosis, and strokelike episodes. Mol Cell Biol 12:480-490

Kirino Y, Yasukawa T, Ohta S et al (2004) Codon-specific translational defect caused by a wobble modification deficiency in mutant tRNA from a human mitochondrial disease. Proc Natl Acad Sci U S A 101: 15070-15075

Koga A, Koga Y, Akita Y et al (2003) Increased mitochondrial processing intermediates associated with three tRNA(Leu(UUR)) gene mutations. Neuromuscul Disord 13:259-262

Konovalova S, Tyynismaa H (2013) Mitochondrial aminoacyl-tRNA synthetases in human disease. Mol Genet Metab 108:206-211 
Kopajtich R, Nicholls TJ, Rorbach J et al (2014) Mutations in GTPBP3 cause a mitochondrial translation defect associated with hypertrophic cardiomyopathy, lactic acidosis, and encephalopathy. Am J Hum Genet 95:708-720

Kruse B, Narasimhan N, Attardi G (1989) Termination of transcription in human mitochondria: identification and purification of a DNA binding protein factor that promotes termination. Cell 58:391-397

Lamichhane TN, Blewett NH, Crawford AK et al (2013a) Lack of tRNA modification isopentenyl-A37 alters mRNA decoding and causes metabolic deficiencies in fission yeast. Mol Cell Biol 33:2918-2929

Lamichhane TN, Mattijssen S, Maraia RJ (2013b) Human cells have a limited set of tRNA anticodon loop substrates of the tRNA isopentenyltransferase TRIT1 tumor suppressor. Mol Cell Biol 33: 4900-4908

Lee KW, Bogenhagen DF (2014) Assignment of 2'-O-methyltransferases to modification sites on the mammalian mitochondrial large subunit 16 S ribosomal RNA (rRNA). J Biol Chem 289:24936-24942

Lee N, Daly MJ, Delmonte T et al (2001) A genomewide linkagedisequilibrium scan localizes the Saguenay-Lac-Saint-Jean cytochrome oxidase deficiency to 2p16. Am J Hum Genet 68:397-409

Lee KW, Okot-Kotber C, LaComb JF, Bogenhagen DF (2013) Mitochondrial ribosomal RNA (rRNA) methyltransferase family members are positioned to modify nascent rRNA in foci near the mitochondrial DNA nucleoid. J Biol Chem 288:31386-31399

Levinger L, Serjanov D (2012) Pathogenesis-related mutations in the Tloops of human mitochondrial tRNAs affect $3^{\prime}$ end processing and tRNA structure. RNA Biol 9:283-291

Levinger L, Giege R, Florentz C (2003) Pathology-related substitutions in human mitochondrial tRNA(Ile) reduce precursor $3^{\prime}$ end processing efficiency in vitro. Nucl Acids Res 31:1904-1912

Levinger L, Oestreich I, Florentz C, Morl M (2004) A pathogenesisassociated mutation in human mitochondrial tRNALeu(UUR) leads to reduced 3 '-end processing and CCA addition. J Mol Biol 337: $535-544$

Li X, Guan M-X (2002) A human mitochondrial GTP binding protein related to tRNA modification may modulate phenotypic expression of the deafness-associated mitochondrial 12S rRNA mutation. Mol Cell Biol 22:7701-7711

Li X, Li R, Lin X, Guan M-X (2002) Isolation and characterization of the putative nuclear modifier gene MTO1 involved in the pathogenesis of deafness-associated mitochondrial $12 \mathrm{~S}$ rRNA A1555G mutation. J Biol Chem 277:27256-27264

Lin CL, Wang Y-T, Yang W-Z, Hsiao Y-Y, Yuan HS (2012) Crystal structure of human polynucleotide phosphorylase: insights into its domain function in RNA binding and degradation. Nucl Acids Res 40:4146-4157

Ling J, Roy H, Qin D et al (2007) Pathogenic mechanism of a human mitochondrial tRNAPhe mutation associated with myoclonic epilepsy with ragged red fibers syndrome. Proc Natl Acad Sci U S A 104:15299-15304

Litonin D, Sologub M, Shi Y et al (2010) Human mitochondrial transcription revisited: only TFAM and TFB2M are required for transcription of the mitochondrial genes in vitro. J Biol Chem 285:18129-18133

Mancuso M, Filosto M, Mootha VK et al (2004) A novel mitochondrial tRNAPhe mutation causes MERRF syndrome. Neurology 62:21192121

Masters BS, Stohl LL, Clayton DA (1987) Yeast mitochondrial RNA polymerase is homologous to those encoded by bacteriophages T3 and T7. Cell 51:89-99

Merante F, Petrova-Benedict R, MacKay N et al (1993) A biochemically distinct form of cytochrome oxidase (COX) deficiency in the Saguenay-Lac-Saint-Jean region of Quebec. Am J Hum Genet 53: 481-487

Mercer TR, Neph S, Dinger ME et al (2011) The human mitochondrial transcriptome. Cell 146:645-658
Metodiev MD, Lesko N, Park CB et al (2009) Methylation of 12S rRNA is necessary for in vivo stability of the small subunit of the mammalian mitochondrial ribosome. Cell Metab 9:386-397

Minczuk M, Piwowarski J, Papworth MA et al (2002) Localisation of the human hSuv3p helicase in the mitochondrial matrix and its preferential unwinding of dsDNA. Nucl Acids Res 30:5074-5086

Minczuk M, Lilpop J, Boros J, Stepien PP (2005) The 5' region of the human hSUV3 gene encoding mitochondrial DNA and RNA helicase: promoter characterization and alternative pre-mRNA splicing. Biochim Biophys Acta 1729:81-87

Minczuk M, He J, Duch AM et al (2011) TEFM (c17orf42) is necessary for transcription of human mtDNA. Nucl Acids Res 39:4284-4299

Montoya J, Christianson T, Levens D, Rabinowitz M, Attardi G (1982) Identification of initiation sites for heavy-strand and light-strand transcription in human mitochondrial DNA. Proc Natl Acad Sci U S A 79:7195-7199

Mollers M, Maniura-Weber K, Kiseljakovic E, et al (2005) A new mechanism for mtDNA pathogenesis: impairment of post-transcriptional maturation leads to severe depletion of mitochondrial tRNASer(UCN) caused by T7512C and G7497A point mutations. Nucl Acids Res 33:5647-5658

Montoya J, Gaines GL, Attardi G (1983) The pattern of transcription of the human mitochondrial rRNA genes reveals two overlapping transcription units. Cell 34:151-159

Mootha VK, Lepage P, Miller K et al (2003) Identification of a gene causing human cytochrome c oxidase deficiency by integrative genomics. Proc Natl Acad Sci U S A 100:605-610

Moraes CT, Ciacci F, Silvestri G et al (1993) Atypical clinical presentations associated with the MELAS mutation at position 3243 of human mitochondrial DNA. Neuromuscul Disord 3:43-50

Morin C, Mitchell G, Larochelle J et al (1993) Clinical, metabolic, and genetic aspects of cytochrome C oxidase deficiency in SaguenayLac-Saint-Jean. Am J Hum Genet 53:488-496

Mourier A, Ruzzenente B, Brandt T, Kühlbrandt W, Larsson N-G (2014) Loss of LRPPRC causes ATP synthase deficiency. Hum Mol Genet 23:2580-2592

Nagaike T, Suzuki T, Tomari Y et al (2001) Identification and characterization of mammalian mitochondrial tRNA nucleotidyltransferases. J Biol Chem 276:40041-40049

Nagaike T, Suzuki T, Katoh T, Ueda T (2005) Human mitochondrial mRNAs are stabilized with polyadenylation regulated by mitochondria-specific poly(A) polymerase and polynucleotide phosphorylase. J Biol Chem 280:19721-19727

Nakai Y, Umeda N, Suzuki T et al (2004) Yeast Nfs1p is involved in thiomodification of both mitochondrial and cytoplasmic tRNAs. J Biol Chem 279:12363-12368

Neeve VCM, Pyle A, Boczonadi V et al (2013) Clinical and functional characterisation of the combined respiratory chain defect in two sisters due to autosomal recessive mutations in MTFMT. Mitochondrion 13:743-748

Nicholls TJ, Minczuk M (2014) In D-loop: 40 years of mitochondrial 7S DNA. Exp Gerontol 56:175-181

Nicholls TJ, Rorbach J, Minczuk M (2013) Mitochondria: mitochondrial RNA metabolism and human disease. Int J Biochem Cell Biol 45: 845-849

Ofengand J, Bakin A (1997) Mapping to nucleotide resolution of pseudouridine residues in large subunit ribosomal RNAs from representative eukaryotes, prokaryotes, archaebacteria, mitochondria and chloroplasts. J Mol Biol 266:246-268

Ojala D, Montoya J, Attardi G (1981) tRNA punctuation model of RNA processing in human mitochondria. Nature 290:470-474

O'Sullivan M, Rutland P, Lucas D et al (2015) Mitochondrial m.1584A $12 \mathrm{~S}$ m62A rRNA methylation in families with $\mathrm{m} .1555 \mathrm{~A}>\mathrm{G}$ associated hearing loss. Hum Mol Genet 24:1036-1044 
Pagliarini DJ, Calvo SE, Chang B et al (2008) A mitochondrial protein compendium elucidates complex I disease biology. Cell 134:112123

Parisi MA, Xu B, Clayton DA (1993) A human mitochondrial transcriptional activator can functionally replace a yeast mitochondrial HMG-box protein both in vivo and in vitro. Mol Cell Biol 13: 1951-1961

Patton JR, Bykhovskaya Y, Mengesha E, Bertolotto C, Fischel-Ghodsian N (2005) Mitochondrial myopathy and sideroblastic anemia (MLASA): missense mutation in the pseudouridine synthase 1 (PUS1) gene is associated with the loss of tRNA pseudouridylation. J Biol Chem 280:19823-19828

Perez-Cerda C, Garcia-Villoria J, Ofman R et al (2005) 2-Methyl-3hydroxybutyryl-CoA dehydrogenase (MHBD) deficiency: an Xlinked inborn error of isoleucine metabolism that may mimic a mitochondrial disease. Pediatr Res 58:488-491

Piekna-Przybylska D, Decatur WA, Fournier MJ (2008) The 3D rRNA modification maps database: with interactive tools for ribosome analysis. Nucl Acids Res 36:D178-183

Posse V, Shahzad S, Falkenberg M, Hallberg BM, Gustafsson CM (2015) TEFM is a potent stimulator of mitochondrial transcription elongation in vitro. Nucl Acids Res 43:2615-2624

Poulsen JB, Andersen KR, Kjaer KH et al (2011) Human 2'-phosphodiesterase localizes to the mitochondrial matrix with a putative function in mitochondrial RNA turnover. Nucl Acids Res 39:3754-3770

Powell CA, Nicholls TJ, Minczuk M (2015) Nuclear-encoded factors involved in post-transcriptional processing and modification of mitochondrial tRNAs in human disease. Front Genet 6:79

Putz J, Florentz C, Benseler F, Giege R (1994) A single methyl group prevents the mischarging of a tRNA. Nat Struct Biol 1:580-582

Rackham O, Davies SM, Shearwood AM, Hamilton KL, Whelan J, Filipovska A (2009) Pentatricopeptide repeat domain protein 1 lowers the levels of mitochondrial leucine tRNAs in cells. Nucl Acids Res 37:5859-5867

Raimundo N, Song L, Shutt TE et al (2012) Mitochondrial stress engages E2F1 apoptotic signaling to cause deafness. Cell 148:716-726

Rauschenberger K, Scholer K, Sass JO et al (2010) A non-enzymatic function of 17beta-hydroxysteroid dehydrogenase type 10 is required for mitochondrial integrity and cell survival. EMBO Mol Med 2:51-62

Reiter V, Matschkal DMS, Wagner M et al (2012) The CDK5 repressor CDK5RAP1 is a methylthiotransferase acting on nuclear and mitochondrial RNA. Nucl Acids Res 40:6235-6240

Rorbach J, Minczuk M (2012) The post-transcriptional life of mammalian mitochondrial RNA. Biochem J 444:357-373

Rorbach J, Nicholls TJ, Minczuk M (2011) PDE12 removes mitochondrial RNA poly(A) tails and controls translation in human mitochondria. Nucl Acids Res 39:7750-7763

Rorbach J, Gammage PA, Minczuk M (2012) C7orf30 is necessary for biogenesis of the large subunit of the mitochondrial ribosome. Nucl Acids Res 40:4097-4109

Rorbach J, Bobrowicz AJ, Pearce S, Minczuk M (2014) Polyadenylation in bacteria and organelles. In Rorbach J, Bobrowicz AJ ed. Methods in Molecular Biology Polyadenylation, 211-227

Rorbach J, Boesch P, Gammage PA et al (2014b) MRM2 and MRM3 are involved in biogenesis of the large subunit of the mitochondrial ribosome. Mol Biol Cell 25:2542-2555

Rossmanith W (2011) Localization of human RNase Z isoforms: dual nuclear/mitochondrial targeting of the ELAC2 gene product by alternative translation initiation. PLoS One 6, e19152

Rossmanith W, Holzmann J (2009) Processing mitochondrial (t) RNAs. Cell Cycle 8:1650-1653

Rossmanith W, Karwan RM (1998) Impairment of tRNA processing by point mutations in mitochondrial tRNA(Leu)(UUR) associated with mitochondrial diseases. FEBS Lett 433:269-274
Ruzzenente B, Metodiev MD, Wredenberg A et al (2012) LRPPRC is necessary for polyadenylation and coordination of translation of mitochondrial mRNAs. EMBO J 31:443-456

Sampson JR, Uhlenbeck OC (1988) Biochemical and physical characterization of an unmodified yeast phenylalanine transfer RNA transcribed in vitro. Proc Natl Acad Sci U S A 85:1033-1037

Sanchez MI, Mercer TR, Davies SM et al (2011) RNA processing in human mitochondria. Cell Cycle 10:2904-2916

Sasarman F, Antonicka H, Shoubridge EA (2008) The A3243G tRNALeu(UUR) MELAS mutation causes amino acid misincorporation and a combined respiratory chain assembly defect partially suppressed by overexpression of EFTu and EFG2. Hum Mol Genet 17:3697-3707

Sasarman F, Brunel-Guitton C, Antonicka H, Wai T, Shoubridge EA (2010a) LRPPRC and SLIRP interact in a ribonucleoprotein complex that regulates posttranscriptional gene expression in mitochondria. Mol Biol Cell 21:1315-1323

Sasarman F, Brunel-guitton C, Antonicka H, Wai T, Shoubridge EA, Consortium L (2010b) LRPPRC and SLIRP interact in a ribonucleoprotein complex that regulates posttranscriptional gene expression in mitochondria. Mol Biol Cell 21:1315-1323

Sasarman F, Nishimura T, Antonicka H, Weraarpachai W, Shoubridge EA, Consortium L (2015a) Tissue-specific responses to the LRPP $\mathrm{RC}$ founder mutation in French Canadian Leigh syndrome. Hum Mol Genet 24:480-491

Sasarman F, Thiffault I, Weraarpachai W et al (2015b) The 3' addition of CCA to mitochondrial tRNASer(AGY) is specifically impaired in patients with mutations in the tRNA nucleotidyl transferase TRNT1. Hum Mol Genet 24:2841-2847

Schapira AH (2006) Mitochondrial disease. Lancet 368:70-82

Schaller A, Desetty R, Hahn D, et al (2011) Impairment of mitochondrial tRNAIle processing by a novel mutation associated with chronic progressive external ophthalmoplegia. Mitochondrion 11:488--496

Schara U, von Kleist-Retzow J-C, Lainka E et al (2011) Acute liver failure with subsequent cirrhosis as the primary manifestation of TRMU mutations. J Inherit Metab Dis 34:197-201

Schild C, Hahn D, Schaller A et al (2014) Mitochondrial leucine tRNA level and PTCD1 are regulated in response to leucine starvation. Amino Acids 46:1775-1783

Sciacco M, Bonilla E, Schon EA, DiMauro S, Moraes CT (1994) Distribution of wild-type and common deletion forms of mtDNA in normal and respiration-deficient muscle fibers from patients with mitochondrial myopathy. Hum Mol Genet 3:13-19

Seidel-Rogol BL, McCulloch V, Shadel GS (2003) Human mitochondrial transcription factor B1 methylates ribosomal RNA at a conserved stem-loop. Nat Genet 33:23-24

Seneca S, Abramowicz M, Lissens W, Muller MF, Vamos E, de Meirleir L (1996) A mitochondrial DNA microdeletion in a newborn girl with transient lactic acidosis. J Inherit Metab Dis 19:115-118

Shi Y, Dierckx A, Wanrooij PH et al (2012) Mammalian transcription factor $\mathrm{A}$ is a core component of the mitochondrial transcription machinery. Proc Natl Acad Sci U S A 109:16510-16515

Shu Z, Vijayakumar S, Chen CF, Chen PL, Lee WH (2004) Purified human SUV3p exhibits multiple-substrate unwinding activity upon conformational change. Biochemistry 43:4781-4790

Shutt TE, Gray MW (2006) Homologs of mitochondrial transcription factor B, sparsely distributed within the eukaryotic radiation, are likely derived from the dimethyladenosine methyltransferase of the mitochondrial endosymbiont. Mol Biol Evol 23:1169-1179

Sinha A, Köhrer C, Weber MHW et al (2014) Biochemical characterization of pathogenic mutations in human mitochondrial methionyltRNA formyltransferase. J Biol Chem 289:32729-32741

Sirum-Connolly K, Mason TL (1993) Functional requirement of a sitespecific ribose methylation in ribosomal RNA. Science 262:18861889 
Sissler M, Helm M, Frugier M, Giege R, Florentz C (2004) Aminoacylation properties of pathology-related human mitochondrial tRNA(Lys) variants. RNA 10:841-853

Slavotinek AM, Garcia ST, Chandratillake G et al (2014) Exome sequencing in 32 patients with anophthalmia/microphthalmia and developmental eye defects. Clin Genet. doi:10.1111/cge.12543

Slomovic S, Schuster G (2008) Stable PNPase RNAi silencing: its effect on the processing and adenylation of human mitochondrial RNA. RNA 14:310-323

Slomovic S, Laufer D, Geiger D, Schuster G (2005) Polyadenylation and degradation of human mitochondrial RNA: the prokaryotic past leaves its mark. Mol Cell Biol 25:6427-6435

Small ID, Peeters N (2000) The PPR motif - a TPR-related motif prevalent in plant organellar proteins. Trends Biochem Sci 25:46-47

Smith AC, Blackshaw JA, Robinson AJ (2012) MitoMiner: a data warehouse for mitochondrial proteomics data. Nucl Acids Res 40: D1160-1167

Sohm B, Frugier M, Brule H, Olszak K, Przykorska A, Florentz C (2003) Towards understanding human mitochondrial leucine aminoacylation identity. J Mol Biol 328:995-1010

Sondheimer N, Fang JK, Polyak E, Falk MJ, Avadhani NG (2010) Leucine-rich pentatricopeptide-repeat containing protein regulates mitochondrial transcription. Biochemistry 49:7467-7473

Spahr H, Habermann B, Gustafsson CM, Larsson NG, Hallberg BM (2012) Structure of the human MTERF4-NSUN4 protein complex that regulates mitochondrial ribosome biogenesis. Proc Natl Acad Sci U S A 109:15253-15258

Spencer AC, Spremulli LL (2004) Interaction of mitochondrial initiation factor 2 with mitochondrial fMet-tRNA. Nucl Acids Res 32:5464 5470

Spinola M, Galvan A, Pignatiello C et al (2005) Identification and functional characterization of the candidate tumor suppressor gene TRIT1 in human lung cancer. Oncogene 24:5502-5509

Sterky FH, Ruzzenente B, Gustafsson CM, Samuelsson T, Larsson N-G (2010) LRPPRC is a mitochondrial matrix protein that is conserved in metazoans. Biochem Biophys Res Commun 398:759-764

Suzuki T, Suzuki T (2014) A complete landscape of post-transcriptional modifications in mammalian mitochondrial tRNAs. Nucl Acids Res 42:7346-7357

Suzuki T, Wada T, Saigo K, Watanabe K (2002) Taurine as a constituent of mitochondrial tRNAs: new insights into the functions of taurine and human mitochondrial diseases. EMBO J 21:6581-6589

Suzuki T, Nagao A, Suzuki T (2011) Human mitochondrial tRNAs: biogenesis, function, structural aspects, and diseases. Annu Rev Genet 45:299-329

Szczesny RJ, Obriot H, Paczkowska A et al (2007) Down-regulation of human RNA/DNA helicase SUV3 induces apoptosis by a caspaseand AIF-dependent pathway. Biol Cell 99:323-332

Szczesny RJ, Borowski LS, Brzezniak LK et al (2010) Human mitochondrial RNA turnover caught in flagranti: involvement of hSuv3p helicase in RNA surveillance. Nucl Acids Res 38:279-298

Taylor RW, Pyle A, Griffin H et al (2014) Use of whole-exome sequencing to determine the genetic basis of multiple mitochondrial respiratory chain complex deficiencies. JAMA 312:68-77

Temperley RJ, Seneca SH, Tonska K et al (2003) Investigation of a pathogenic mtDNA microdeletion reveals a translation-dependent deadenylation decay pathway in human mitochondria. Hum Mol Genet 12:2341-2348

Temperley RJ, Wydro M, Lightowlers RN, Chrzanowska-Lightowlers ZM (2010) Human mitochondrial mRNAs-like members of all families, similar but different. Biochim Biophys Acta 1797:1081-1085

Terzioglu M, Ruzzenente B, Harmel J et al (2013) MTERF1 binds mtDNA to prevent transcriptional interference at the light-strand promoter but is dispensable for rRNA gene transcription regulation. Cell Metab 17:618-626
Tiranti V, Savoia A, Forti F et al (1997) Identification of the gene encoding the human mitochondrial RNA polymerase (h-mtRPOL) by cyberscreening of the expressed sequence tags database. Hum Mol Genet 6:615-625

Tischner C, Hofer A, Wulff V et al (2015) MTO1 mediates tissue specificity of OXPHOS defects via tRNA modification and translation optimization, which can be bypassed by dietary intervention. Hum Mol Genet 24:2247-2266

Tomari Y, Hino N, Nagaike T, Suzuki T, Ueda T (2003) Decreased CCAaddition in human mitochondrial tRNAs bearing a pathogenic A4317G or A10044G mutation. J Biol Chem 278:16828-16833

Tomecki R, Dmochowska A, Gewartowski K, Dziembowski A, Stepien PP (2004) Identification of a novel human nuclear-encoded mitochondrial poly(A) polymerase. Nucl Acids Res 32:6001-6014

Tucker EJ, Hershman SG, Köhrer C et al (2011) Mutations in MTFMT underlie a human disorder of formylation causing impaired mitochondrial translation. Cell Metab 14:428-434

Tuppen HA, Naess K, Kennaway NG et al (2012) Mutations in the mitochondrial tRNA Ser(AGY) gene are associated with deafness, retinal degeneration, myopathy and epilepsy. Eur J Hum Genet 20: 897-904

Umeda N, Suzuki T, Yukawa M, Ohya Y, Shindo H, Watanabe K (2005) Mitochondria-specific RNA-modifying enzymes responsible for the biosynthesis of the wobble base in mitochondrial tRNAs. Implications for the molecular pathogenesis of human mitochondrial diseases. J Biol Chem 280:1613-1624

Urbonavicius J (2003) Transfer RNA modifications that alter +1 frameshifting in general fail to affect -1 frameshifting. RNA 9: $760-768$

Urbonavicius J, Qian Q, Durand JM, Hagervall TG, Bjork GR (2001) Improvement of reading frame maintenance is a common function for several tRNA modifications. EMBO J 20:4863-4873

Uusimaa J, Jungbluth H, Fratter C et al (2011) Reversible infantile respiratory chain deficiency is a unique, genetically heterogenous mitochondrial disease. J Med Genet 48:660-668

Vanlander AV, Menten B, Smet J et al (2014) Two siblings with homozygous pathogenic splice site variant in mitochondrial asparaginyltRNA synthetase (NARS2). Hum Mutat 36:222-231

Vedrenne V, Gowher A, De Lonlay P et al (2012) Mutation in PNPT1, which encodes a polyribonucleotide nucleotidyltransferase, impairs RNA import into mitochondria and causes respiratory-chain deficiency. Am J Hum Genet 91:912-918

Vilardo E, Nachbagauer C, Buzet A, Taschner A, Holzmann J, Rossmanith W (2012) A subcomplex of human mitochondrial RNase $\mathrm{P}$ is a bifunctional methyltransferase-extensive moonlighting in mitochondrial tRNA biogenesis. Nucl Acids Res 40:1158311593

Villarroya M, Prado S, Esteve JM et al (2008) Characterization of human GTPBP3, a GTP-binding protein involved in mitochondrial tRNA modification. Mol Cell Biol 28:7514-7531

von Ameln S, Wang G, Boulouiz R et al (2012) A mutation in PNPT1, encoding mitochondrial-RNA-import protein PNPase, causes hereditary hearing loss. Am J Hum Genet 91:919-927

Wang Z, Cotney J, Shadel GS (2007) Human mitochondrial ribosomal protein MRPL12 interacts directly with mitochondrial RNA polymerase to modulate mitochondrial gene expression. J Biol Chem 282:12610-12618

Wang DD-h, Shu Z, Lieser A, Chen P-1, Lieser SA, Lee W-h (2009) Human mitochondrial SUV3 and polynucleotide phosphorylase form a $330-\mathrm{kDa}$ heteropentamer to cooperatively degrade doublestranded RNA with a $3^{\prime}$-to-5' directionality. J Biol Chem 284: 20812-20821

Wanrooij PH, Uhler JP, Simonsson T, Falkenberg M, Gustafsson CM (2010) G-quadruplex structures in RNA stimulate mitochondrial transcription termination and primer formation. Proc Natl Acad Sci U S A 107:16072-16077 
Wilson WC, Hornig-Do HT, Bruni F et al (2014) A human mitochondrial poly(A) polymerase mutation reveals the complexities of posttranscriptional mitochondrial gene expression. Hum Mol Genet 23:6345-6355

Wydro M, Bobrowicz A, Temperley RJ, Lightowlers RN, ChrzanowskaLightowlers ZM (2010) Targeting of the cytosolic poly(A) binding protein PABPC1 to mitochondria causes mitochondrial translation inhibition. Nucl Acids Res 38:3732-3742

Xu F, Morin C, Mitchell G, Ackerley C, Robinson BH (2004) The role of the LRPPRC (leucine-rich pentatricopeptide repeat cassette) gene in cytochrome oxidase assembly: mutation causes lowered levels of COX (cytochrome c oxidase) I and COX III mRNA. Biochem J 382:331-336

Xu F, Ackerley C, Maj MC et al (2008a) Disruption of a mitochondrial RNA-binding protein gene results in decreased cytochrome $b$ expression and a marked reduction in ubiquinol-cytochrome $\mathrm{c}$ reductase activity in mouse heart mitochondria. Biochem J 416:15-26

Xu Z, O'Farrell HC, Rife JP, Culver GM (2008b) A conserved rRNA methyltransferase regulates ribosome biogenesis. Nat Struct Mol Biol 15:534-536

Yakubovskaya E, Guja KE, Mejia E et al (2012) Structure of the essential MTERF4:NSUN4 protein complex reveals how an MTERF protein collaborates to facilitate rRNA modification. Structure 20:1940 1947

Yan H, Zareen N, Levinger L (2006a) Naturally occurring mutations in human mitochondrial pre-tRNASer(UCN) can affect the transfer ribonuclease $Z$ cleavage site, processing kinetics, and substrate secondary structure. J Biol Chem 281:3926-3935

Yan Q, Bykhovskaya Y, Li R et al (2006b) Human TRMU encoding the mitochondrial 5-methylaminomethyl-2-thiouridylatemethyltransferase is a putative nuclear modifier gene for the phenotypic expression of the deafness-associated $12 \mathrm{~S}$ rRNA mutations. Biochem Biophys Res Commun 342:1130-1136

Yang SY, He XY, Schulz H (2005) Multiple functions of type 10 17betahydroxysteroid dehydrogenase. Trends Endocrinol Metab 16:167175

Yarham JW, Elson JL, Blakely EL, McFarland R, Taylor RW (2010) Mitochondrial tRNA mutations and disease. Wiley Interdiscip Rev RNA 1:304-324
Yarham JW, Lamichhane TN, Pyle A et al (2014) Defective i6A37 modification of mitochondrial and cytosolic tRNAs results from pathogenic mutations in TRIT1 and its substrate tRNA. PLoS Genet 10, e1004424

Yasukawa T, Suzuki T, Ishii N, Ueda T, Ohta S, Watanabe K (2000a) Defect in modification at the anticodon wobble nucleotide of mitochondrial tRNA(Lys) with the MERRF encephalomyopathy pathogenic mutation. FEBS Lett 467:175-178

Yasukawa T, Suzuki T, Ueda T, Ohta S, Watanabe K (2000b) Modification defect at anticodon wobble nucleotide of mitochondrial tRNAs(Leu)(UUR) with pathogenic mutations of mitochondrial myopathy, encephalopathy, lactic acidosis, and stroke-like episodes. J Biol Chem 275:4251-4257

Yasukawa T, Suzuki T, Ishii N, Ohta S, Watanabe K (2001) Wobble modification defect in tRNA disturbs codon-anticodon interaction in a mitochondrial disease. EMBO J 20:4794-4802

Yasukawa T, Kirino Y, Ishii N, et al (2005) Wobble modification deficiency in mutant tRNAs in patients with mitochondrial diseases. FEBS Lett 579:2948-2952

Yokoyama S, Watanabe T, Murao K et al (1985) Molecular mechanism of codon recognition by tRNA species with modified uridine in the first position of the anticodon. Proc Natl Acad Sci U S A 82:4905-4909

Zeharia A, Shaag A, Pappo O et al (2009) Acute infantile liver failure due to mutations in the TRMU gene. Am J Hum Genet 85:401-407

Zhu HY, Wang SW, Liu L, et al (2009) A mitochondrial mutation A4401G is involved in the pathogenesis of left ventricular hypertrophy in Chinese hypertensives. Eur J Hum Genet 17:172-178

Zlotkin SH, Anderson GH (1982) Sulfur balances in intravenously fed infants: effects of cysteine supplementation. Am J Clin Nutr 36: $862-867$

Zlotkin SH, Cherian MG (1988) Hepatic metallothionein as a source of zinc and cysteine during the first year of life. Pediatr Res 24:326329

Zschocke J (2012) HSD10 disease: clinical consequences of mutations in the HSD17B10 gene. J Inherit Metab Dis 35:81-89

Zschocke J, Ruiter JP, Brand J et al (2000) Progressive infantile neurodegeneration caused by 2-methyl-3-hydroxybutyryl-CoA dehydrogenase deficiency: a novel inborn error of branched-chain fatty acid and isoleucine metabolism. Pediatr Res 48:852-855 